\title{
VALIDATION OF THE SELF-COMPASSION SCALE: \\ CORRELATIONS WITH THE BECK DEPRESSION INVENTORY-II
}

\author{
A Thesis \\ presented to \\ the Faculty of California Polytechnic State University, \\ San Luis Obispo
}

\author{
In Partial Fulfillment \\ of the Requirements for the Degree \\ Master of Science in Psychology
}

by

Pär D. Andréasson

November 2012 
(C) 2012

Pär D. Andréasson

ALL RIGHTS RESERVED 


\section{COMMITTEE MEMBERSHIP}

TITLE:

AUTHOR:

DATE SUBMITTED:

COMMITTEE CHAIR:

COMMITTEE MEMBER:

COMMITTEE MEMBER:
Validation of the Self-Compassion Scale: Correlations with the Beck Depression Inventory-II

Pär D. Andréasson

November 1, 2012

Jason Williams, $\mathrm{PhD}$.

Michael Selby, PhD.

J. Kelly Moreno, PhD. 


\section{ABSTRACT \\ VALIDATION OF THE SELF-COMPASSION SCALE: CORRELATIONS WITH THE BECK DEPRESSION INVENTORY-II}

\section{Pär Daniel Andréasson}

Self-compassion denotes a compassionate and empathic attitude toward oneself (Neff, 2003b). In the past decade, the Self-Compassion Scale (SCS) has been used to measure self-compassion in individuals and its effects on social, psychological, and physiological functioning. While many studies have found positive effects of high selfcompassion showing promise for the use of the construct in clinical and empirical applications, there is a dearth of literature regarding the psychometric properties of the SCS. Furthermore, previous studies have not evaluated the individual subscales of the SCS as they relate to other inventories. This study evaluated the SCS and its subscales in relation the to the well-established Beck Depression Inventory II (BDI-II). The study included 142 undergraduate Cal Poly students who completed both the SCS and the BDIII. As predicted, a statistically significant negative correlation was found between total SCS and BDI-II scores $(r=-.57)$. Statistically significant negative correlations were also found between BDI-II total scores and the Self-Kindness $(r=-.35)$, Common Humanity ( $r$ $=-.37$ ), and Mindfulness ( $r=-.35)$ subscales of the SCS. Statistically significant positive correlations were found with BDI-II total scores and the Self-Judgment $(r=.49)$, Isolation $(r=.59)$ and Over-Identified $(r=.43)$ subscales of the SCS. This study evaluated the convergent and discriminant validity of the SCS and its subscales as compared to the BDI-II.

Keywords: Self-Compassion, Depression, Beck Depression Inventory II, SelfCompassion Scale, Self-Kindness, Self-Judgment, Common Humanity, Isolation, Mindfulness, Over-Identification. 


\section{ACKNOWLEDGMENTS}

I would like to thank all of my thesis committee members for their time, guidance, and support. In particular, I thank Dr. Jason Williams for all of his efforts and patience in helping this thesis come to fruition. I would also like to thank the Psychology and Child Development Department at Cal Poly, and particularly the professors in the MS program.

Lastly, I thank my family and friends who have supported me throughout the program including my coursework, clinical training, and completion of this thesis project. 


\section{TABLE OF CONTENTS}

LIST OF TABLES.

\section{CHAPTER}

I. INTRODUCTION

Definition of Terms..................................................... 3

II. LITERATURE REVIEW................................................................ 4

The Self-Compassion Scale................................................ 4

Self-Compassion and Mindfulness..................................... 5

Self-Compassion and Self-Esteem...................................... 11

Self-Compassion and General Psychological Functioning...... 14

Self-Compassion and the Treatment of Psychopathology........ 15

Self-Compassion, Mindulness, and Relational Functioning.... 17

Self-Compassion and Physical Health.................................. 21

Self-Compassion as Clinical Self-Care................................. 22

Statement of the Problem...................................................... 23

Hypotheses.................................................................. 24

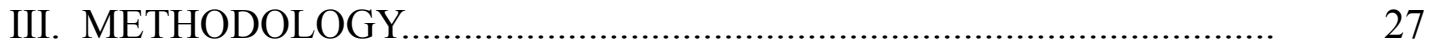

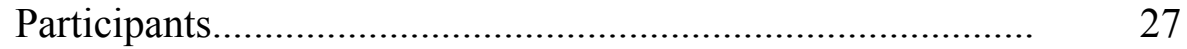

Instruments................................................................... 27

Design and Procedure.................................................... $\quad 30$

IV. RESULTS.............................................................................. 32

V. DISCUSSION ......................................................................... 37

VI. REFERENCES............................................................................. 48

\section{APPENDICES}

A. Informed Consent Form......................................................... 69

B. Self-Compassion Scale........................................................ $\quad 70$ 


\section{LIST OF TABLES}

Figure

Page

1. Descriptive Analysis of Measures........................................................ 66

2. Intercorrelations Between SCS and BDI-II Scales and Subscales............. 67

3. Intercorrelations Between SCS and BDI-II Scores for Males and

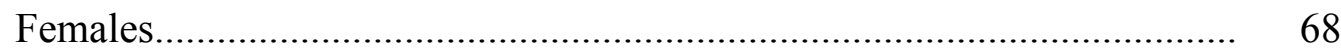




\section{INTRODUCTION}

Self-compassion is a construct drawn from the Buddhist tradition, describing compassion for oneself. As compassion is characterized by understanding, acceptance, and forgiveness extended to others (McKay \& Fanning, 1992), self-compassion entails the same attributes of compassion turned inward (Neff \& McGeehee, 2010). Neff (2003b) describes self-compassion as encompassing self-kindness, common humanity, and mindfulness in opposition to self-judgment, isolation, and over-identification. As such, the Self-Compassion Scale (SCS) contains all of these aspects as separate yet related subscales. While most individuals may relate to the notion of compassion and empathy towards others, affording the same kind of treatment towards oneself may be more novel. The construct of self-compassion regarding individual, relational, and physiological functioning is an exciting development in psychology.

While the notion of self-compassion is integral to eastern thought and religion, it has only become commonplace in western psychology in recent years. Kristin Neff is the most prolific scholar and empiricist concerning the construct. According to Neff (2009), self-compassion implies movement and motivation towards balance, health, and wellbeing for oneself. The self-compassionate individual meets their own feelings of inadequacy, suffering, or shortcomings with understanding and insight as opposed to criticism and judgment (Neff, 2009). Although awareness of one's suffering is a prerequisite to addressing it, self-compassion implies not over-identifying with one's emotional state (Neff, 2003a). Being self-compassionate should not be confused with self-centeredness (Neff, 2003b), nor should it be thought of as akin to self-pity (Goldstein 
\& Kornfield, 1987). The definition and expression of self-compassion seems to fall somewhere in between, reminiscent of the Buddhist concept of the middle path (Hanh, 1997).

The distinction between compassion for self and others is less pronounced in the Buddhist tradition. Some explain this phenomenon as arising from a focus on interdependence over independence, characteristic of eastern philosophy and religion (Salzberg, 1997). While compassion for others is emphasized, the Buddhist tradition also underscores the need for self-compassion. This has traditionally been held as a prerequisite to maintaining the capacity for compassion towards others (BennettGoleman, 2001; Brach, 2003; Hanh, 1997; Neff, 2003b). Intuitively, one would expect self-compassion and compassion towards others to be correlated. However, some studies have reported minimal correlations between the two constructs (Wei, Liao, Ku, \& Shaffer, 2011). While the notion of compassion for the self may seem to be foreign to western thought, the relationship and dynamics of one's relationship to oneself is fundamental idea that appears in most schools of psychology. As a relatively new construct in empirical and research psychology, however, much remains to be explored and understood regarding self-compassion.

New psychological constructs need to be clearly operationalized and measurable to be appropriate for both empirical and clinical applications. The SCS (Neff, 2003b) has made research and applications of self-compassion more feasible. Since its inception, there have been scores of research studies published in the past decade concerning various topics, correlates, and implications of self-compassion. The results have been 
promising for both research and clinical use of self-compassion. The current study evaluates the SCS compared to the Beck Depression Inventory II (BDI-II). This study evaluates the SCS and its subscales with the well-known BDI-II. This comparison allows for both convergent and discriminant validity of the SCS to be evaluated. Evaluating the psychometric properties of the SCS provides ground upon which continued study may ensue.

\section{Definition of Terms}

Self-Compassion is a construct drawn from the Buddhist tradition. It describes a compassionate attitude towards oneself characterized by acceptance of one's perceived shortcomings, inadequacies, failures, and suffering as being part of the human condition (Neff, 2003b). Self-compassion involves offering the same kindness one may extend to loved ones to oneself in spite of weaknesses, imperfections, and flaws. Furthermore, it is characterized by an openness to and nurturing of these aspects of self (Neff \& Vonk, 2009).

Major Depression is defined by The Diagnostic and Statistical Manual of Mental Disorders-IV-TR as consisting of some or all of the following symptoms: subjective feelings of sadness and/or emptiness, anhedonia, significant weight gain or loss, insomnia or hypersomnia, feeling restlessness or physical agitation, fatigue or energy loss, feelings of worthlessness or excessive guilt, difficulty concentrating, and thoughts of suicide (American Psychiatric Association, 2000). 


\section{LITERATURE REVIEW}

\section{The Self-Compassion Scale}

The Self Compassion Scale (SCS) was designed by Neff (2003b) to measure selfcompassion in individuals. The SCS has been used in a number of studies within the past decade amid developments in the applications of meditation and mindfulness in western psychology. The result has been a growing interest in the topic of self-compassion and its relationship to psychological functioning and phenomena. Since 2003, scores of studies have used the SCS as a measure of self-compassion with respect to a variety of psychological phenomena, measures, and tests. These findings will be discussed in detail in the sections to follow.

The SCS is informed by Buddhist psychology and understanding of the self. This is evident in the phrasing of items on the scale and the structure of the measure. Furthermore, during its development factor analysis dictated that it be divided into six subscales including: self-kindness, self-judgment, common humanity, isolation, mindfulness, and over-identification (Neff, 2003b). Thus, the six subscales are the result of both theoretical and empirical findings. A total SCS score and subscale scores can be derived from the measure providing detail regarding the construct and its theoretical makeup. Furthermore, these subscales offer clinicians more precise attributes of the construct to be measured. The inventory offers flexibility and breadth in its utilization. Research findings regarding the SCS subscales illustrate this notion.

Empirical use of individual SCS subscales has yielded some interesting results. For example, Van Dam, Sheppard, Forsyth, and Earleywine (2011) reported that the SCS 
was a better predictor of symptom severity and quality of life than the Mindful Attention Awareness Scale (MAAS). Ying (2009) reported that the over-identification subscale was significantly correlated with depressive symptom level, while participants' overidentification and isolation scores were found to significantly correlate with their sense of coherence and self-efficacy. Thus, the subscales of the SCS make it a multidimensional inventory beyond the main construct measure of self-compassion.

The SCS has a number of benefits for its use including ease of administration. The measure is completed by self-report and can be administered in a short amount of time. Although the original measure is only twenty-six items long, a short form of the SCS has also been developed. The short version shows high internal consistency and near-perfect correlation with the original (Raes, Pommier, Neff, \& Van Gucht, 2011). The SCS has also been used successfully cross-culturally. It has been translated into a number of other languages and been applied to a variety of cultures and ethnic groups (Deniz, Kesici, \& Sümer, 2008). Cross-cultural studies using the SCS have revealed some cultural differences in the expression and levels of self-compassion (Neff, Pisitsungkagarn, \& Hsieh, 2008). Research findings and clinical uses of the SCS globally indicate the utility of the measure for exploring the affects and correlates of selfcompassion.

\section{$\underline{\text { Self-Compassion and Mindfulness }}$}

Mindfulness is strongly associated with the concept of self-compassion. Some have asserted that self-compassion naturally entails mindfulness as it involves awareness of one's suffering in the present moment without judgment (Brown \& Ryan, 2003; Hayes, 
Strosahl, \& Wilson, 1999; Kabat-Zinn, 1994). Mindfulness has been described as "paying attention in a particular way: on purpose, in the present moment, and nonjudgmentally" (Kabat-Zinn, 1994, p. 4). Bishop et al. (2004) proposed a two-component operational definition of mindfulness involving self-regulated attention while maintaining an attitude - characterized by curiosity, openness, and acceptance - towards phenomena experienced in the present moment. Moreover, mindfulness is characterized by bringing a heightened quality of attention to the experience of every present moment (Kabat-Zinn, 1990), leading to greater clarity and acceptance of reality (Kabat-Zinn, 1994). The precise relationship between self-compassion and mindfulness was recently explored by Hollis-Walker and Colosimo (2011). They reported that self-compassion partially mediates the relationship between mindfulness and psychological well-being. This illustrates some of the relationship between mindfulness and self-compassion.

Despite its popularity in recent years, the concept of mindfulness can be challenging to translate. Some have defined mindfulness as the "English equivalent of the Pali words sati and sampajana, which as a whole can be translated as awareness, circumspection, discernment, and retention" (Shapiro \& Carlson, 2009, p. 4). The SCS subscale mindfulness is designed to measure this construct as part of self-compassion (Neff, 2003b). The corresponding negative subscale for mindfulness is entitled overidentification. These subscales represent both directions of the same construct on a continuum. While mindfulness describes an awareness of one's emotional and mental state in the present moment, over-identification denotes being overcome and overtaken by emotional reactivity (Neff, 2003b). Over-identification can result in being distanced 
from others, oneself, and external phenomena. Meanwhile, mindfulness denotes a more objective view of internal and external phenomena as opposed to rigid subjectivity in one's experience (Bennett-Goleman, 2001). Mindfulness practices are thought to provide insight into the transient and fluid nature of mental and emotional processes opposed to a fixed view of the self and perceived reality (Segal, Williams, \& Teasdale, 2002; Teasdale, 1999; Teasdale, Segal, Williams, \& Mark 1995). Thich Nhat Hanh (2006) describes this dynamic poetically as, "When sunlight shines, it helps all vegetation grow. When mindfulness shines, it transforms all mental formations" (p. 217). Self-knowledge, observation, and awareness of one's own mental process in the present moment is thought to have wide-reaching possibilities concerning mental, physical, and relational well-being (Siegel, 2010). Given the degree of overlap and interconnection both theoretically and empirically between self-compassion and mindfulness, research findings regarding mindfulness will be discussed in further detail.

Mindfulness has become a considerable focus in clinical and empirical psychology in the past two decades (Allen et al., 2006; Baer, 2003; Bishop et al., 2004). While mindfulness is traditionally rooted in Buddhist spiritual practices and akin to meditation (Hanh, 1976), contemporary uses of mindfulness include many clinical applications (Bishop et al., 2004). These are generally aimed at bringing awareness and developing capacities to consciously transform problematic cognitions, emotions, and behaviors (Kabat-Zinn, 1994). Mindfulness applied to mental health is described by Siegel (2010) as, "When we embrace the idea that developing the mind toward health entails moving our inner world toward integration, then we can see how a strengthened 
mindsight lens can be essential for identifying when we're in chaos and rigidity" (p. 119). The view of this internal lens is aimed at bringing acceptance and peace to our own inner processes without being controlled by them.

Many applications of mindfulness focus on emotion regulation (ER), with the premise that most psychological challenges affect, or are affected by, ER (Repetti, Taylor, \& Seeman, 2002). The most prominent clinical application of mindfulness is in Dialectical Behavior Therapy (Linehan, 1993) for the treatment of borderline personality disorder (Linehan, Armstrong, Saurez, Allmon, \& Heard, 1991). However, many other mindfulness-based interventions exist for the treatment of emotional and behavioral challenges (Kabat-Zinn, 1998). For example, many mindfulness-based studies have been shown to be effective in the prevention of major depression relapse (Ma \& Teasdale, 2004; Segal et al., 2002; Teasdale et al., 2000). Mindfulness approaches have also been shown to be effective in treating anxiety (Evans et al., 2008; Kabat-Zinn, 1990), substance abuse disorders (Hayes et al., 1999), psychosis (Bach \& Hayes, 2002; Gaudiano \& Herbert, 2006), and eating disorders (Fairburn, Cooper, \& Shafran, 2003; Kristeller \& Hallett, 1999; Telch, Agras, \& Linehan, 2001). Hofmann, Sawyer, Witt, \& Oh (2010) performed a meta-analysis of 39 studies of patients treated with mindfulnessbased therapies. Results showed large effect sizes in treating patients with anxiety and depressive disorders. Meanwhile, Orzech, Shapiro, Brown, \& McKay (2009) reported reductions in anxiety with increases in subjective well-being and self-compassion a month after intensive mindfulness training with a geriatric population. 
Mindfulness-based Cognitive Therapy (MBCT) is another prominent clinical application used with a variety of different diagnoses and challenges (Kuken et al., 2008; Ma \& Teasdale, 2004; Teasdale et al., 2000). MBCT was designed to prevent depression relapse by training patients to meet distressing thoughts and feelings with patience and empathy (Segal et al., 2002). MBCT has been used successfully in group-based depression relapse prevention (Segal et al., 2002), and has demonstrated similar outcomes to antidepressant medications in the treatment of depression (Kuyken et al., 2008). Kuyken et al. (2010) found that increases in mindfulness and self-compassion mediated the effect of MBCT on depressive symptoms after a 15-month interval, while reducing subjects' cognitive reactivity.

Mindfulness has also shown a number of promising applications concerning nonclinical populations (Chambers, Gullone, \& Allen, 2009) including: lowering the intensity and frequency of negative affect (Brown \& Ryan, 2003; Chambers, Lo, \& Allen, 2008), reductions in anxiety (Shapiro et al., 1998), coping with stress (Davidson et al., 2003) and improvements in romantic relational functioning (Cordova \& Jacobson, 1993). Furthermore, Brown, Ryan, Creswell, and Niemiec (2008) reported that mindfulness was negatively correlated with ego-defensiveness when under perceived threat. HollisWalker and Colosimo (2011) reported that scores of mindfulness (using the Five-Factor Mindfulness Questionnaire) were associated with levels of self-compassion $(r=.69)$, psychological well-being $(r=.75)$, agreeableness $(r=.36)$, extraversion $(r=.42)$, openness $(r=.35)$, conscientiousness $(r=.46)$, and with lower levels of neuroticism 
$(r=-.66)$ measured by the SCS, Psychological Well Being scale, and the NEOPersonality Inventory-Revised, respectively. Birnie, Speca, \& Carlson (2010) demonstrated that Mindfulness-Based Stress Reducation (MBSR) treatments were correlated with increases in self-compassion, perspective-taking abilities, and levels of spirituality. These studies illustrate some of the promising associations between selfcompassion, mindfulness, and psychological well-being.

The most widely researched clinical applications of mindfulness is MindfulnessBased Stress Reduction (MBSR). Though MBSR was originally developed for the use of chronic pain management (Kabat-Zinn, 1982; Kabat-Zinn, Lipworth, Burney, \& Sellers, 1987), it has also been used to treat many other physical and psychological challenges. MBSR has demonstrated effectiveness in reducing state and trait anxiety, reducing overall psychological distress, and increasing overall empathy levels in premedical students (Shapiro, Schwartz, \& Bonner, 1998). Biegel, Brown, Shapiro, and Schubert (2009) reported that MBSR reduced self-reported levels of anxiety, depression, and somatic distress and improved sleep quality and self-esteem in adolescent psychiatric outpatients. The same study found that patients treated with MBSR as opposed to a treatment-as-usual group showed higher levels of improvement after a 5-month followup. Kimbrough, Magyari, Langenberg, Chesney, and Berman (2010) found that MBSR over an 8-week period resulted in reductions in depressive symptoms, numbing, and avoidance with adult survivors of childhood sexual abuse. In addition, MBSR has been shown to be effective in reducing mood disturbances and stress levels in cancer patients (Speca, Carlson, Goodey, \& Angen, 2000). 
Neurological studies have elucidated structural brain changes and mental processing as a result of meditation and mindfulness. Using fMRI techniques to analyze brain activity during mindfulness meditation, Hölzel et al. (2007) found increases in activation in both the anterior cingulate and medial prefrontal cortex. Moreover, pronounced differences were found in these brain areas when comparing experienced meditators to novices. Long-term mindfulness meditation has also been demonstrated to increase cortical thickness (Lazar, 2005) and hippocampus grey matter (ㅂ̈zel et al.). Furthermore, compassion for self and others has shown increased activity and stimulation in regions of the brain linked with joy and optimism (Lutz, Greischar, Rawlings, Ricard, \& Davidson, 2004). Mindfulness has also been linked to improvements in mental processing, attention, and memory. Moore and Malinowsky (2008) reported that high levels of mindfulness assessed by the Kentucky Inventory of Mindfulness Skills inventory were positively correlated with high processing speed $(r=.51)$, high attentional acuity $(r=.62)$ inhibitory control $(r=.67)$, and good coordination of speed in a performance task $(r=.331)$. Increases in attentional and working memory have also been reported (Chambers et al., 2008). These studies show the possible effects of mindfulness and its related constructs such as self-compassion.

\section{Self-Compassion and Self-Esteem}

Self-esteem is closely related to the construct of self-compassion. Selfcompassion has been found to correlate with measures of self-esteem $(r=.62)$ using the SCS and the Rosenburg Self-Esteem Scale (Neff, 2009). Similar findings between the two constructs were reported by Leary, Tate, Adams, Allen, and Hitchcock (2007). 
Although self-esteem is well established has generally been regarded as an integral measure of psychological health (Neff, 2003a; Neff, 2009), self-compassion offers some important differences. For example, self-compassion has been described as a better measure of personal and relational wellbeing than self-esteem (Neff, 2003a). Selfcompassion is theorized as being less dependent on contingencies such as status or income than self-esteem (Neff, 2009). While self-esteem has traditionally been used as a measure of an individual's state of being, self-compassion is more focused on how one relates to oneself over time. Furthermore, self-compassion is concerned with how one relates to oneself in spite of life's challenges or contingencies (Neff, 2003a). Thus, selfcompassion has also been described as a more stable measure of self-worth and wellbeing over time (Neff \& Vonk, 2009). As some have remarked that efforts to increase selfesteem in individuals have not been particularly effective (Swann, 1996), increasing selfcompassion may be a useful adjunct or alternative.

The theoretical differences between self-compassion and self-esteem are reflected in research findings. Many scholars have been critical of self-esteem as a measure of psychological health (e.g. Baumeister, Smart, \& Boden, 1996; Damon, 1995; Ellis \& London, 1993; Finn, 1990; Hewitt, 1998; McMillan, Singh, \& Simonetta, 1994; Neff; 2003a; Neff, 2009; Seligman, 1995, Swann, 1996). While high self-esteem has generally been viewed as a wholly positive attribute, some studies have elucidated some of its challenges. High self-esteem has been found to be associated with ego-defensiveness and narcissism (Leary et al., 2007; Neff, 2003). Contrarily, self-compassion functions as a buffer against ego threat (Neff, Kirkpatrick, \& Rude, 2006). Furthermore, Neff (2003b) 
found self-compassion to be negatively correlated with neurotic perfectionism. The same study also showed that self-esteem was significantly correlated with narcissism as opposed to self-compassion. Leary et al. (2007) reported similar findings, of higher correlations between self-esteem narcissism $(r=.37)$ than self-compassion and narcissism $(r=.18)$. Thus, although self-esteem is usually highly regarded and wellestablished in the psychological community, its negative correlates may not be as desirable (Baumeister \& Vohs, 2001; Crocker \& Park, 2004).

Scholars have pointed to a number of other problems with employing self-esteem as a measure of well-being. Scholars have warned against overemphasizing the development of self-esteem as it could lead to self-absorption and lack of concern for others (Damon, 1995; Seligman, 1995). High self-esteem has been linked to increased prejudice against out-groups, violence against those perceived to threaten the ego, and distortions in self-awareness (Aberson, Healy, \& Romero, 2000; Baumeister, Bushman, \& Campbell, 2000; Baumeister et al., 1996; Sedikides, 1993). Meanwhile those high in self-compassion have been found to make more accurate self-evaluations (Leary et al., 2007). Another criticism of self-esteem is that it often involves making judgments and comparisons between self and others (Coopersmith, 1967; Harter, 1999). In contrast, self-compassion emphasizes the universality of suffering as part of the human condition, and de-emphasizes social comparison (Neff, 2003a). These findings and the critiques of self-esteem point to the importance of exploring self-compassion as a measure of psychological well-being. 


\section{Self-Compassion and General Psychological Functioning}

A number of studies in the past decade have begun to identify correlations and defining characteristics of self-compassion in individual psychological functioning. Neff, Rude, and Kirkpatrick (2007) found self-compassion to be significantly associated with higher levels of happiness, optimism, positive mood, personal initiative, curiosity, and exploration. Self-compassion is associated with well-being among both adolescents and adults (Neff \& McGeeHee, 2010). Meanwhile, high incidences of childhood physical abuse, emotional abuse, and neglect have been found to correlate with lower levels of self-compassion later in life (Tanaka, Wekerle, Schmuck, \& Paglia-Boak, 2011). Selfcompassion has been found to correlate positively with self-efficacy (Iskender, 2009). Neff, Hsieh, and Dejitterat (2004) reported that self-compassion is positively correlated with perceived competence and negatively correlated with fear of failure. The same study reported that individuals high in self-compassion were more focused on mastery than performance goals in a learning context.

High self-compassion in individuals has been linked to increases in social connectedness, and decreases in self-criticism, rumination, thought suppression, and anxiety (Neff, Kirkpatrick, \& Rude, 2007). Leary et al. (2007) reported that individuals with high self-compassion have also been found to judge themselves less critically in creative performance tasks than those with low self-compassion. Those high in selfcompassion were also less likely to ruminate about negative feedback and had lower emotional responses to both real and imagined negative events. Furthermore, it was demonstrated that self-compassion mitigated negative emotions when receiving neutral 
feedback. Self-compassion is negatively correlated with proneness to shame, fear of failure, body consciousness, and negative self-evaluations (Mosewich, Kowalski, Sabiston, Sedgwick, \& Tracy, 2011). Overall, studies have shown advantages to high self-compassion in individuals and their psychological functioning.

\section{Self-Compassion and the Treatment of Psychopathology}

In recent years, the utility of self-compassion in working with various pathologies has been evaluated. Self-compassion has been described as being effective in promoting emotional regulation as it mitigates negative emotions and promotes more positive feelings of kindness and human connection (Neff et al., 2005). Raes (2011) reported that levels of self-compassion significantly predicted either the development or reduction of depressive symptoms within a 5-month period among university students. Selfcompassion was demonstrated as being a protective factor regarding anxiety related to personal weaknesses. The same study showed that increases in self-compassion were strongly correlated with numerous other indicators of mental health including reductions in negative affect, depression, and rumination (Neff, Kirkpatrick, \& Rude, 2007). Raes (2010) reported that brooding mediated the relationship between self-compassion and depression. Birnie et al. (2010) reported that levels of self-compassion in participants after Mindfulness Based Stress Reduction therapy were significantly positively correlated with spirituality and mindfulness, and negatively correlated with stress and mood disturbances. High levels of self-compassion have also been found to be significantly negatively correlated with neuroticism $(r=-.65)$ measured by the NEO Five-Factor 
Inventory. The same study also found significant correlations with self-compassion to both extroversion $(\mathrm{r}=.32)$ and conscientiousness $(r=.42$; Neff, Rude, et al., 2007).

Specific treatment models have been designed with self-compassion in mind. One of the more prominent treatment models is Compassionate Mind Training (CMT). CMT incorporates self-compassion as a primary component of its treatment interventions (Gilbert \& Procter, 2006). Gilbert and Procter reported reductions in depression, anxiety, inferiority, and shame using CMT to treat high self-criticism and shame in clients. A qualitative study with individuals experiencing auditory hallucinations reported that CMT aided participants in transforming perceived voices into being less malevolent (Mayhew \& Gilbert, 2008). A ten-week group intervention based on CMT also demonstrated significant improvements in depression and social comparison measured by the Social Comparison Scale and the Beck Depression Inventory, respectively (Laithwaite et al., 2009).

Many other clinical applications of self-compassion are promising. One qualitative study with a clinical population described self-compassion as being a meaningful construct with many participants commenting on its potential to increase selfacceptance (Pauley \& McPherson, 2010). Research inquiry into treating personality disorders with self-compassion has also ensued. Schanche, Stiles, McCullough, Svartberg, and Nielsen (2011) reported the development of self-compassion in individuals diagnosed with Cluster $\mathrm{C}$ personality disorders significantly predicted reductions of psychiatric symptoms, personality pathology, and relational challenges after 
therapy. Although the specific use of self-compassion in clinical applications is still being explored, results are promising thus far.

\section{Self-Compassion, Mindfulness, and Relational Functioning}

Self-compassion and its effect on relationships and attachment patterns is another promising area of research. Similar to the discourse on self-esteem, scholars have critiqued the western emphasis on the individual as opposed to the collective, citing that an overemphasis on the self may lead to overlooking aspects of relationship and community (Fancher, 1995; Richardson, Fowers, \& Guignon, 1999). The concepts of self-compassion and mindfulness may provide a bridge between self and others. Gambrel and Keeling (2010) assert that highly mindful people may be more empathic, aware, and sensitive to the needs of others resulting in higher relational satisfaction. In support of this idea, many recent studies have shown significant correlations between mindfulness levels and reported relationship satisfaction (Barnes, Brown, Krusemark, Campbell, \& Rogge, 2007; Burpee \& Langer, 2005; Wachs \& Cordova, 2007). In further examining the relationship between mindfulness and relationship satisfaction, Wachs and Cordova (2007) reported significant positive associations between mindfulness and marital satisfaction, empathy, perspective taking, and control of anger. Reductions in relational challenges with self-compassion focused treatments have also been documented with those diagnosed with personality disorders (Schanche et al., 2011). Baker and McNulty (2011) found self-compassion to be associated with motivation to resolve interpersonal challenges, constructive problem-solving, and marital stability. Self-compassionate individuals have been demonstrated to show more 
willingness to accept responsibility for negative events and make more accurate selfevaluations (Leary et al., 2007).

The relationship between self-compassion and attachment styles has also been studied. Bowlby (1988) stressed the importance of early experiences with caregivers as they can have longstanding effects on an individual's perception of value to others and worthiness of care. Furthermore, these experience can lead to pronounced attachment styles such as anxious and avoidant (Brennan, Clark, \& Shaver, 1998). These attachment styles are linked to physical and mental health outcomes (Feeney, 2000; Huntsinger \& Leuken, 2004). These observations are consistent with the finding that individuals with anxious attachment styles have more difficulty with self-kindness than those with secure attachments (Neff \& McGehee, 2010). Raque-Bogdan, Ericson, Jackson, Martin, \& Bryan (2011) evaluated the interrelationships between attachment styles, mattering, physical health, and mental health. This study demonstrated that self-compassion partially mediated the relationship between attachment and mental health. Selfcompassion was also found to correlate with mattering $(r=.34, p<.01)$ and mental health $(r=.55, p<.01)$, as measured by the Mattering Scale and the Medical Outcomes Short Form respectively. Clearly, self-compassion affects relational functioning in various ways and shows potential in mitigating relationship challenges.

Other interesting relational findings have also been reported regarding attachment styles. Shaver, Lavy, Saren, and Mikulincer (2007) reported that mindfulness scores (using the Five-Factor Mindfulness Questionnaire) were negatively correlated with attachment anxiety and avoidant attachment. Walsh, Balint, Smolira, Fredricksen, and 
Madsen (2009) found total mindfulness scores (using the MAAS) were negatively correlated with attachment anxiety $(r=-.32)$ and attachment avoidance $(r=-.25)$ using the Experience in Close Relationships Questionnaire-Revised. Self-compassion has also been found to mediate the relationship between adult attachment anxiety and subjective well-being (Wei et al., 2011). Similarly, high attachment anxiety and avoidance were found to negatively correlated with self-compassion in a sample of college students (Raque-Bogdan et al., 2011).

Self-compassion and mindfulness practices have been assessed regarding the parent-child relationship and family relational dynamics. Some have asserted that mindfulness practices may improve a parent's ability to establish emotional connection with their children while keeping their own emotional reactivity under control (Altmaier \& Maloney, 2007). Mindful parenting has been described as having the following attributes: "listening with full attention, nonjudgmental acceptance of self and child, emotional awareness of self and child, self regulation in the parenting relationship, and compassion for self and child" (Duncan, Coatsworth, \& Greenberg, 2009, p. 258). One qualitative study of mindfulness practices shows its potential in increasing attachment between parents and their infant children after childbirth (Hughes et al., 2009). Greco and Eifert (2004) point to the use of mindfulness interventions to disrupt maladaptive relational patterns between couples and families with children. These strategies can be used in therapy to counteract the tendency for experiential avoidance such as attempts to suppress, alter, or avoid thoughts, memories, and bodily sensations (Hayes \& Wilson, 
1994). Furthermore, mindfulness-based interventions for families who have or are experiencing trauma may also be beneficial (Pigni, 2010).

Some research has been focused on mindfulness-based approaches to parenting and the parent-child relationship. Mindfulness training for children with ADHD and their parents has demonstrated to increase compliance and decrease stress levels leading to decreases in prescribed medications during the study's mindfulness training period (Singh et al., 2010). Singh et al. (2009) showed that training parents in mindfulness resulted in improved parent-child interactions. Specific programs have also been designed around mindfulness and parenting. The Mindfulness Parenting Program (MPP) (Placone-Willey, 2002) is a manual-based intervention program aimed at teaching parenting skills supported by breathing exercises, body awareness, and other aspects of mindfulness practice designed to improve parent-child interactions. Although the efficacy of MPP with various populations has been evaluated (Altmaier \& Maloney, 2007), results have been inconclusive for a variety of reasons. Methodological concerns have been reported regarding mindfulness applications with children and adolescents (Burke, 2010). Gambrel \& Keeling (2010) warn that correlational studies used in mindfulness-based relational studies should be interpreted carefully. In conclusion, although the impact of self-compassion and mindfulness is promising, the effects of specific interventions for couples and families are yet to be clearly understood and demonstrated (Sawyer-Cohen \& Semple, 2010). 


\section{Self-Compassion and Physical Health}

The relationship between self-compassion and physiological health is another promising area of research. Costa and Pinto-Gouveia (2010) reported a number of interesting results regarding self-compassion and chronic pain. Their findings suggested that those with higher levels of pain acceptance (measured with the Chronic Pain Acceptance Questionnaire) scored significantly higher on SCS measures of self-kindness, common humanity, and mindfulness, with corresponding lower scores on the selfjudgment, isolation, and over-identification subscales of the measure. Wright et al. (2011) reported that scores of self-compassion scores significantly predicted negative affect, positive affect, pain catastrophizing, and pain disability. Also, those high in selfcompassion showed higher levels of self-efficacy relating to pain management. Selfcompassion research aimed at treating eating disorders has also shown promise in reducing restricting behaviors (Adams \& Leary, 2007). Meanwhile, MBSR has been shown effective in managing chronic pain (Kabat-Zinn, 1982; Kabat-Zinn et al., 1987), and in treating fibromyalgia (Kaplan, Goldenberg, \& Galvin-Nadeau, 1993). Terry and Leary (2011) point to self-compassion as promoting better physical health outcomes by helping individuals to seek treatment, accept diagnoses, and regulate emotion more readily. Furthermore, self-compassionate individuals have been found to be linked with increased personal initiative (Neff, Rude, et al., 2007) which may affect behaviors that could positively affect health seeking behaviors (Terry \& Leary, 2011). Beyond MBSR interventions, more inquiry needs to be made regarding self-compassion and physical health. 


\section{Self-Compassion as Clinical Self-Care}

Self-compassion is a potentially important construct related to self-care for caregivers, medical, and mental health professionals. Self-compassion has been described as being integral to counselor self-care, allowing clinicians to mitigate occupational stress (Patsiopoulos \& Buchanan, 2011). Considering these challenges, some scholars emphasize the potential affect of self-compassion for caregivers to ameliorate stress and promote self-care (Halifax, 2011). Some studies have been directly focused on self-compassion concerning medical professionals. For instance, selfcompassion was shown to correlate positively $(r=.55)$ with emotional intelligence in nurses (using the Trait Emotional Intelligence Questionnaire) (Heffernan, Griffin, McNulty, \& Fitzpatrick, 2010). Shapiro et al. (1998) have pointed to stress reduction through meditation to ameliorate the development of depression and anxiety in health professionals. Furthermore, Shepherd and Cardon (2009) propose the development of self-compassion for use by individuals and organizations to learn from experience when confronted with project failure.

Regarding clinicians, mindfulness has been referred to as a "crucial ingredient in the therapy relationship, and as a technology for psychotherapists to cultivate personal therapeutic qualities (Germer, Siegal, \& Fulton, 2005, p. 9). This has been presented as being both a therapeutic intervention and as clinician self-care simultaneously. Shapiro and Carlson (2009) describe mindfulness as an effective self-care strategy for clinicians in the health care field. They point to the tendency of health care professionals to devote considerable resources in caring for their patients while neglecting their own needs, often 
leading to compassion fatigue experienced by clinicians (Figley, 2002; Weiss, 2004).

Thus, evaluating and addressing self-compassion in caregivers has wide reaching implications beyond the scope of treating others. The same principles of self-compassion and mindfulness that have been described in detail above apply equally to clinicians and caregivers. Ironically, caring for others may sometimes result in neglecting our own needs.

\section{Statement of the Problem}

The construct of self-compassion has recently become widely researched and applied to clinical settings. While the development of the SCS has spawned further interest in the topic and enabled researchers to measure self-compassion, there is a dearth of literature regarding the psychometrics of the inventory. The psychometrics of the SCS were reported by Neff (2003b) who created the inventory, although further analyses are needed to provide a complete understanding of its properties. No previous study has analyzed the SCS and its subscales with regard to the well-established BDI-II and its cognitive-affective and somatic-vegetative subscales. Furthermore, prior studies have not reported on specific SCS subscale scores as they relate to other inventories.

Further research and in-depth analyses into the validity of the SCS and its subscales in relation to more established measures are needed. Although some studies have utilized the BDI-II (Raes, 2011), the BDI-I (Neff, 2003b, Neff \& McGeHee, 2010; Van Dam, Sheppard, Forsyth, \& Earleywine, 2011) and the Zung Self-Rating Depression Scale (Neff, Pisitsungkagarn, \& Hsieh, 2008) with regard to the SCS, only Neff (2003b), set out to evaluate the psychometrics of the SCS. While assessment scales and 
inventories such as the SCS can provide invaluable information both empirically and clinically, further analyses of psychometrics must be performed. Furthermore, ongoing psychometric assessment should be performed by multiple parties in addition to the author of the SCS to provide more rigorous testing of the inventory.

Given that self-compassion and the SCS are gaining momentum in clinical and empirical applications, it is vital that its psychometric properties are evaluated. The current study evaluates the six subscales and the total score of the SCS with regard to the well-established BDI-II and its cognitive-affective and somatic-vegetative subscales. This study reports on the discriminant and convergent validity of the SCS and its subscales in relation to the BDI-II.

\section{Hypotheses}

The current study proposed three main hypotheses:

Hypothesis 1. The study predicted a negative correlation between total scores on the SCS and the BDI-II. This is the primary hypothesis of the study. This is based on findings in previous studies performing comparisons between the SCS and BDI-II total scores (Van Dam et al., 2011) and other related measures of depression (Neff et al., 2007). A measure such as the SCS which evaluates an individual's level of selfcompassion should be expected to be inversely associated to a measure of depression severity such as the BDI-II especially given that they represent some of the distinguishing attributes of depression (American Psychiatric Association, 2000). This idea is also supported by the finding that emotional balance is positively associated with levels of self-compassion (Leary et al., 2007). 
The main hypothesis also predicted negative correlations between SCS total scores and both the Cognitive-Affective and Somatic-Vegetative subscales (Dozois, Dobson, \& Ahnberg, 1998) of the BDI-II. These predictions are based upon findings that these and similarly divided subscales of the BDI-II tend to be very strongly correlated with the total scores of the BDI-II (Brouwer, Meijer, \& Zevalkink, 2012). These findings suggest that SCS total scores should be negatively associated with the aforementioned BDI-II subscales.

Hypothesis 2. The study predicted a positive correlation between the SelfJudgment, Isolation, and Over-Identified SCS sub-scales with total scores on the BDI-II. This hypothesis is based in evaluating the convergent validity of the SCS as compared with the BDI-II. The three "negative" subscales of the SCS should be positively associated with increasing levels of depression. This hypothesis is based on previously reported findings comparing the above subscales of the SCS with levels of depression (Neff et al., 2008).

Hypothesis 3. The study predicted a negative correlation between the SelfKindness, Common Humanity, and Mindfulness SCS sub-scales with total scores on the BDI-II. This hypothesis in based in evaluating the discriminant validity of the SCS as compared with the BDI-II. Those scoring high in these subscales of the SCS would be expected have lower depression scores. This prediction is also based on similar findings by Neff et al. (2008) who used the Zung Self-Rating Depression Scale. The present study predicted to find similar results using the BDI-II to assess depression severity. This 
hypothesis is also supported by findings reported by Neff et al. (2007) concerning "positive" psychological functioning and self-compassion. 


\section{METHODOLOGY}

\section{Participants}

The sample included 142 undergraduate psychology students (38 male, 104 female) at Cal Poly State University, drawn from three undergraduate psychology courses. Students either participated to complete course credit or were offered extra credit points. No identifying information on questionnaire packets such as names or student identification numbers were collected. Questionnaire packets were distributed over the course of approximately two months. This survey-based study was approved by the Cal Poly Human Subjects Committee before data collection. Questionnaires included an Informed Consent form (see Appendix A) informing students of their right to either participate or not participate in the study. Information regarding any potential harmful effects of participation was also conveyed, and a list of community resources such as low-cost counseling centers were provided.

\section{$\underline{\text { Instruments }}$}

The present study used two psychological inventories including the SelfCompassion Scale and the Beck Depression Inventory II.

The Self Compassion Scale. The Self-Compassion Scale (SCS) is a 26-item scale is designed to measure self-compassion (Neff, 2003; see Appendix B). The SCS is designed to derive a total score of self-compassion while also assessing the subscales self-kindness, self-judgment, common humanity, isolation, mindfulness, and overIdentification (Neff, 2003b). Items for self-judgment, over-identification and isolation are reverse coded, then all subscales are averaged. A total self-compassion score is 
derived by averaging all the item scores. Some items from the SCS include: "When I'm feeling down I tend to obsess and fixate on everything that's wrong" and "I'm intolerant and impatient towards those aspects of my personality I don't like". Responses are given on a 5-point scale from 1 (almost never) to 5 (almost always). Higher total scores represent higher levels of self-compassion.

The SCS demonstrates good validity and reliability cross-culturally (Neff, 2003b; Neff, Pisitsungkagarn, \& Hsieh, 2008). Using Cronbach's alpha, the SCS total score has been found to have high consistency as reported by Van Dam et al. (2011) $(\alpha=.92)$, Neff et al. (2007) ( $\alpha=$.90), and Raes (2009) ( $\alpha=$.94). Internal consistency between items is high for each of the subscales of the SCS including: self-kindness $(\alpha=.83)$, selfjudgment ( $\alpha=.75)$, common humanity $(\alpha=.76)$, isolation $(\alpha=.73)$, mindfulness $(\alpha=.72)$, and over-identification $(\alpha=.72)$ (Van Dam et al., 2011). The SCS has demonstrated good test-retest reliability over both a three-week period $(r=.93$; Neff, 2003a) and a five-month period $(r=.71$; Raes, 2011). SCS results have not been found to show significant differences by gender or ethnicity (Neff et al., 2007), though some subscale differences have been reported regarding culture (Neff et al., 2008).

The Beck Depression Inventory II. The Beck Depression Inventory II (BDI-II) is a 21-item self-report inventory designed to assess the severity of depression and depressive symptomatology (Beck et al., 1996). The inventory assesses a range of psychological and biological functioning including, for example: irritability, changes in appetite and sleep patterns, and concentration difficulty. Sample items under irritability include: "I am no more irritable than usual", "I am more irritable than usual", "I am much 
more irritable than usual", and "I am irritable all the time". Each of the items is rated on a 4-point scale from 0 - 3 with a total possible score of 63 . Higher total scores represent higher levels of depression. Ratings are summed to comprise a total score ranging from 0-63 indicating depression severity. Score ranges for the BDI-II indicating severity of depression are as follows: minimal (0 - 13), mild (4 - 19), moderate (20 - 29), and severe (29 - 63) (Beck, Steer, \& Brown, 1996).

The BDI-II is one of the most widely used depression inventories of its kind and demonstrates high internal consistency (Cronbach $\alpha=.94$ ), with item-total correlations ranging from .54 to .74 (Arnau, Meagher, Norris, \& Bramson, 2001). Similar findings for internal consistency (Cronbach $\alpha=.90$ ) have been reported by Raes (2010). Overall, the BDI-II's well-established reputation has made it a very popular measure for both clinical and research applications (Cusin, Yang, Yeung, \& Fava, 2010). Regarding specific populations, similar reliability figures have been reported with psychiatry outpatients $(\alpha=.92)$ and college students $(\alpha=.93$; Smith $\&$ Erford, 1998). A high testretest correlation $(r=.93)$ was found in a study with outpatients between their first and second week of therapy sessions (Beck et al., 1996). Construct validity testing performed in comparison to the SCL-90-R showed that the BDI-II was more strongly correlated with the depression subscale $(r=.89)$ than the corresponding anxiety subscale $(r=.71)$ of the same measure (Steer, Ball, Ranieri, \& Beck, 1997). Similarly, the BDI-II was found to correlate more strongly with the Hamilton Psychiatric Scale for Depression $(r=.71)$ than the Hamilton Rating Scale for Anxiety $(r=.47)$ (Riskind et al., 1987). The BDI-II 
has not been found to correlate with age $(r=-.03)$ or ethnicity $(r=.04)$ though women have been found to score higher than men (Beck et al., 1996).

The total score of the BDI-II is most often used to assess depression severity, however some factor analysis studies have suggested the use of subscales. Beck, Steer, Brown, and van der Does (2002) suggested the separation of factors into cognitive, somatic, and affective. Ward (2006) used a bi-factor model including somatic and cognitive subscales along with the general score. Though these permutations differ to some degree, the common marker of these factor models is the division of the BDI-II into some form of somatic, affective and cognitive factors (Arnau et al., 2001). The present study uses the two-factor model used by Dozois, Dobson, and Ahnberg (1998) which divides the scale into Cognitive-Affective and Somatic-Vegetative factors. Scholarly debate continues about the use of BDI-II subscales, and while findings tend to be mixed, the total score of the BDI-II is still the dominant indicator of depression severity (Blais, 2011). Furthermore, some advocate using the BDI-II total score in to avoid misleading results (Brouwer et al., 2012).

\section{Design and Procedure}

Participants were administered questionnaires including both the SCS and the BDI-II in randomized to counterbalance the two measures and negate any effects of order on results. Approximately half of participants received packets ordered SCS followed by BDI-II while the other half received packets in the opposite order. Neither the SCS nor the BDI-II bore any markers associated with either inventory and both were simply labeled "Mood Inventory". Participants were asked to complete the questionnaires in 
their classrooms which took approximately 10 to 25 minutes to complete. Classrooms were kept quiet while students completed the questionnaires.

The SCS was scored according to test protocols. Subscale scores were averaged to derive subscale means. A total mean was calculated by adding the raw subscale scores together (after reverse coding the isolation, over-identification, and self-judgment items) and dividing by total number of items. The BDI-II total score was derived by adding together all the item responses. The cognitive-affective and somatic vegetative subscale scores were derived by adding up items comprising each subscale (Dozois et al., 1998). Scores on the SCS and the BDI-II and their corresponding subscales were then evaluated to assess the degree of their associations. 


\section{RESULTS}

Before analyzing the planned comparisons of the hypotheses, both the SCS and the BDI-II were assessed for their internal consistency using Cronbach's alpha. The SCS was found to have high internal consistency between items and the total score $(\alpha=.87)$. This is consistent with previously reported similar alphas (Neff et al., 2007; Neff et al., 2008; Raes, 2009; Van Dam et al., 2010). The BDI-II was also found to have high internal consistency between items and the total score $(\alpha=.89)$. This figure is consostent with previously reported alphas (Arnau et al., 2001; Raes, 2010; Smith \& Erford, 1998). Both the coefficient alphas for the SCS and BDI-II fall within the guidelines for acceptability for clinical purposes (Cicchetti, 1994). A descriptive analysis was also performed to evaluate scores of the entire sample on each scale and subscale (See Table $1)$.

\section{Hypothesis 1}

The first planned comparison predicted a negative correlation between total scores of the SCS and the BDI-II. A Pearson-product correlation was performed resulting in a significant negative correlation $(r=-.57, p<.001)$. This finding indicates that the SCS total score and the BDI-II total scores are significantly and negatively correlated as predicted (See Table 2). This result is very close to the reported correlation between the SCS and the original BDI $(r=-.51, p<.01)$ by Neff $(2003 b)$, as well as comparisons between the SCS total score and the Zung Self-Rating Depression Scale $(r=-.54, p<.01$; Neff, Pisitsungkagarn, \& Hsieh, 2008) 
The main hypothesis also predicted that total SCS scores would be negatively correlated with both the cognitive-affective and somatic-vegetative sub-scales of the BDI-II. The same statistical test yielded significant negative correlations between total SCS scores and the cognitive-affective sub-scale $(r=-.56, p<.001)$ and the somaticvegetative sub-scale $(r=-.50, p<.001)$ of the BDI-II. Interestingly, the correlation value of the total score of the SCS as compared with both the total BDI-II score and the cognitive-affective sub-scale were very similar $(r=-.57$ and $r=-.56$ respectively; See Table 2). Although both of the correlations between the total SCS score and the two subscales of the BDI-II were high, the correlation with the cognitive-affective sub-scale was slightly higher. Overall, these findings contribute to the discriminant validity of the SCS compared to both the BDI-II total and subscale scores.

\section{Hypothesis 2}

Significant positive correlations were found between the BDI-II total score and the self-judgment, isolation, and over-identified sub-scales of the SCS. A Pearsonproduct correlation was calculated between the BDI-II total score and the above three subscales of the SCS. The association between the BDI-II total score and the selfjudgment subscale was found to be significant $(r=.49, p<.001)$. Further, correlations between self-judgment and the cognitive-affective and somatic-vegetative sub-scales of the BDI-II were the highest among the SCS sub-scale scores. Although both results were significant, self-judgment was found to be more closely associated with cognitiveaffective $(r=.54, p<.001)$ than with somatic-vegetative $(r=.39, p<.001$; See Table 2$)$. 
The association between the BDI-II total score and the isolation sub-scale of the SCS was also found to be significant $(r=.59, p<.001)$. The association between the BDI-II total score and the over-identified sub-scale of the SCS was also found to be significant $(r=.43, p<.001$; See Table 2$)$. Results confirm the second hypothesis, showing consistency with the three negative sub-scales of the SCS related to the BDI-II. These findings contribute to the convergent validity of the SCS. Although previous studies have not directly compared these SCS subscales with the cognitive-affective and somatic-vegetative subscales of the BDI-II, the results are consistent with previously reported related findings regarding total scores of the BDI-II (Neff et al., 2007).

\section{Hypothesis 3}

The third hypothesis predicted a negative association between the self-kindness, common humanity, and mindfulness sub-scales of the SCS with regard to BDI-II total scores. The results of Pearson product-correlations calculated to evaluate the degree of association between these measures confirmed these predictions. The association between self-kindness and the BDI-II total score was found to be significant $(r=-.35, p$

$<.001$; See Table 2). The association between common humanity and the BDI-II total score was also found to be significant $(r=-.37, p<.001)$. In addition, the association between mindfulness and the BDI-II total score was found to be significant as well $(r=-$. $35, p<.001)$. These findings show consistency between the three positive sub-scales of the SCS and contribute to the discriminant validity of the scale. These results are consistent with related previous studies (Neff et al., 2007). 


\section{$\underline{\text { Post-Hoc Analyses }}$}

Along with the planned comparisons as part of this study, post-hoc analyses also yielded interesting findings. Pearson-product correlations performed between total BDIII scores and the cognitive-affective and somatic-vegetative sub-scales were both found to be significantly positively correlated $(r=.91, p<.001$ and $r=.95, p<.001)$.

Similarly, correlations between total SCS total scores and the SCS sub-scale scores all yielded strong and significant associations. SCS total scores as compared to each SCS subscale were as follows: self-kindness $(r=.82, p<.001)$, self-judgment $(r=-.84$, $p<.001)$, common humanity $(r=.65, p<.001)$, isolation $(r=-.80, p<.001)$, mindfulness $(r=.78, p<.001)$, and over-identification $(r=-.80, p<.001$; See Table 3$)$.

Gender differences were found concerning several comparisons and statistical tests (See Table 3). Negative associations found between total SCS scores and total BDIII scores were stronger for males $(r=-.67, p<.001)$ than for females $(r=-.54, p<.001)$. Another notable difference between genders was seen in associations with the common humanity subscale of the SCS and total scores for both the BDI-II and the SCS. For females, Pearson-product correlational tests yielded stronger significant associations between common humanity and total scores for the SCS $(r=.70, p<.001)$ and the BDIII $(r=-.44, p<.001)$ as compared to males. For males, the association between common humanity and total SCS score was lower $(r=.57, p<.001)$ than for females. Also, the association between common humanity and the BDI-II for males $(r=-.22$, $p<.184$ ) was considerably lower than for females although not statistically significant. 
Overall mean score differences were also found between genders on both the BDI-II and the SCS (See Table 3$)$. Males $(N=38)$ on average scored slightly higher on the SCS total $(M=2.85, S D=.70)$ compared to females $(N=104)$ on the same measure $(M=2.80, S D=.75)$. Meanwhile men scored lower on the BDI-II $(M=7.89, S D=6.03)$ than females $(M=9.16, S D=8.27)$. Similar differences in total SCS scores between sexes have previously been reported, with females scoring slightly lower than males (Neff 2003a; Neff \& Vonk, 2009; Neff et al., 2005; Raes, 2010). Likewise, the finding of higher average total scores on the BDI-II for females compared to males is also consistent with previously reported findings (Arnau et al., 2001). Further, higher average scores were also found for females $(N=104)$ on the cognitive-affective $(M=3.49, S D=3.91)$ and the somatic-vegetative $(M=5.67, S D=4.92)$ as opposed to males $(N=38)$ on both subscales $(M=3.03, S D=2.81$ and $M=4.87, S D=3.78$ respectively $)$. 


\section{DISCUSSION}

This study evaluated the validity of the SCS and its subscales as they relate to the BDI-II. The SCS and its subscales demonstrated higher convergent validity than discriminant validity as compared with the BDI-II, though all correlations were consistent with the hypotheses. The SCS also showed high internal consistency, consistent with findings from previous studies (e.g. Neff, Kirkpatrick, \& Rude, 2006; Neff et al., 2008; Raes, 2010; Van Dam et al., 2010). Overall, the findings of this study and other similar comparisons (Neff, 2003b; Neff et al., 2008) suggest that the SCS seems to have sound psychometrics as it relates to the BDI-II and may be appropriate for further clinical and empirical applications.

This study yielded a significant negative correlation between the SCS and the BDI-II. Significant negative correlations were also found between the SCS and both the somatic-vegetative and cognitive-affective subscales of the BDI-II. The similarity of correlations between the SCS and the BDI-II total scores and the subscales scores evaluated in this study findings may suggest that the BDI-II total score is sufficient to use when comparing depression and self-compassion. However, it should be noted that many constellations of factors for the BDI-II exist (Arnau et al., 2001; Beck, Steer, Brown, \& van der Does, 2002; Dozois et al., 1998; Ward, 2006). The choice of factor separation in this study could have affected the findings in a variety of ways. Ultimately, the SCS proved to be negatively correlated with the BDI-II and the chosen subscales. The degree of negative correlation between the SCS and the BDI-II in this study may indicate that the 
SCS has sound psychometric properties. However, further evaluation of the SCS's psychometrics beyond the scope of this study would be beneficial.

Given the above findings, it can be expected that those who score high on the SCS should be expected to score low on the BDI-II and vice-versa. This phenomenon can be explained in a couple ways. First, those who are kinder and less judgmental of themselves, along with having higher levels of interconnection with others, and more mindful of their circumstances may experience less depression than others. Meanwhile, those experiencing less depression may exhibit more self-kindness, less isolation, and more mindfulness, etc. While no causal relationship can be inferred from the analyses in the discriminant and convergent validity of the scale appears to be sound with regard to the BDI-II, potentially making it a useful inventory for clinical and empirical use.

The convergent validity of the SCS was demonstrated by comparing the SCS subscales self-judgment, isolation, and over-identified. As expected, all three subscales were found to be positively correlated with BDI-II scores. Although these two inventories are not designed to evaluate the same constructs, the correlation coefficients were relatively strong. These findings show some signs of convergent validity of the above SCS subscales as compared with the BDI-II. This also contributes to the overall validity of the SCS total score, as it is derived by summing the three positive and negative subscale scores of the measure.

The positive correlations between the negative SCS subscales and the BDI-II point to well-established phenomena in psychological theory. For example, selfjudgment and over-identification with emotions have traditionally been related to 
depression in many schools of psychology. For example, the themes of self-judgment and over-identification with emotions is characteristic of rational-emotive (Ellis \& Dryden, 1997) and cognitive-behavioral therapy (Beck, 1963) models respectively. Furthermore, treating isolation by increasing social contact with patients is a primary intervention in working with depressed clients (Jongsma et al., 2006). Results suggest that the isolation subscale inversely correlates with depression more strongly than selfjudgment or over-identification. This finding may point to the social nature of human beings and the importance of connection between individuals, their families, and their communities.

The discriminant validity of the SCS in relation to the BDI-II was also demonstrated by this study. The SCS subscales self-kindness, common humanity, and mindfulness were all evaluated with regard to the BDI-II scores yielding negative correlations in all three cases. Although all statistically significant, these correlation coefficients were much lower than those found with the self-judgment, isolation, and over-identified subscales described above. This result may indicate that the selfjudgment, isolation, and over-identified are more aligned with depressive symptomatology as evaluated by the BDI-II than the self-kindness, common humanity, and mindfulness subscales. However, other factors may have affected this result as explained below.

The correlations between the BDI-II and the self-kindness, common humanity, and mindfulness subscales may have been affected by sensitivity issues regarding the structure of the both the SCS and BDI-II. More specifically, the possible responses for 
each measure differ significantly. The range of responses for the BDI-II only allows for one "positive" response - or rather one response that would not indicate depressive symptomatology - as opposed to the SCS which uses a 5-point Likert scale from almost never to almost always. For example, the first item of the BDI-II for Sadness reads, "(0) I do not feel sad”, “(1) I feel sad much of the time”, “(2) I am sad all the time”, and “ (3) I am so sad or unhappy that I can't stand it". Therefore, responses in the positive direction on the BDI-II are limited to one item response possibility, thus limiting the range of scores in a positive direction. This may have affected the strength of correlations between the BDI-II and the positive SCS subscales of self-kindness, common humanity, and mindfulness. If both measures allowed for positive and negative responses to each item, more balance between the correlations may have been found. While correlational coefficients were much lower for the self-kindness, common humanity, and mindfulness subscales, results demonstrate some discriminant validity properties of the SCS in relation to the BDI-II. While these findings begin to evaluate the psychometrics of the SCS, further analyses are needed.

Overall, the SCS demonstrated high reliability and convergent validity, with relatively lower discriminant validity in relation to the BDI-II. This supports previous findings of the SCS's psychometrics, providing more evidence for its continued use in empirical and clinical applications. This study focused on the relationship between the SCS (a measure of self-compassion) and the BDI-II (a measure of depression). Given the pervasive and often complicated nature of depression, a sound inventory such as the SCS and its subscales could be advantageous in diagnosis, treatment, and the exploration of 
etiology. The clinical implications of a reliable and valid psychological measure like the SCS are potentially wide-reaching as it measures one's fundamental relationship with oneself. Given the correlations between depression and self-compassion found in this study, specific applications of the SCS and considerations of self-compassion may be worthwhile. A general discussion of these potential applications follows a discussion of the limitations of this study.

\section{Limitations}

There are a number of limitations in the present study. The first set of limitations are related to the sample used for the study. The current sample was not diverse regarding race, ethnicity, socioeconomic status, or age. This is based on the source of participants, drawn from undergraduate psychology courses at Cal Poly. Thus, the sample is not representative of the greater population or other university populations. Psychology undergraduates may differ from other populations in a number of ways including interest in taking psychological inventories, levels of depression or selfcompassion, honesty in taking inventories, or other important differences. Furthermore, the fact that students were offered course credit to participate may have affected the sample selection and item responses. The sample source also lead to a particular gender distribution of the sample which was largely female $(n=102$ of 142$)$. This may have affected the data and results especially regarding gender differences on the measures tested in post hoc analyses.

This study evaluated the correlations between the SCS and the BDI-II and their respective subscales. While correlational results indicate the degree of association 
between measures, it is important to understand the implications and limits of the results. For example, the correlation between the SCS and the BDI-II total scores was found to be -.57 . While this is a relatively high correlation coefficient, the proportion of the variance predicted by this relationship is only $32 \%$. Clearly, the SCS and the BDI-II are measure of two related yet distinct constructs, so near-perfect correlations would not be expected. However, it is important to remember the limitations of correlational analyses regarding the implications of the results.

Furthermore, the current study relied heavily on self-reported data and used only the BDI-II and its subscales in evaluating the SCS. This presents a number of challenges. Self-report data has the potential of being inaccurate as participants may intentionally alter their item responses. Participants may have also unintentionally altered their responses based on the testing environment. For example, proximity to classmates or friends may have also affected participants' answers as complete privacy could not be ensured. In addition, participants may have been inclined to finish the inventories more quickly in their classrooms before or after class than if completed in another location or without time constraints. A thorough psychometric evaluation of the SCS would require using multiple inventories, ideally targeting specific subscales, which is beyond the scope of the present study. Despite these limitations, the results of the study support the hypotheses pointing to some interesting applications and future directions of study. General Discussion

The results of this study are particularly important as depression is one of the most prevalent mental health challenges of our time. By 2020, the World Health 
Organization estimates depression to be the leading cause of disability (Rubia, 2009). Depression also shows high comorbidity rates with other psychological disorders and is especially difficult to treat when treatment-resistant (Casher, Gih, \& Agarwala, 2012). Although the BDI-II is commonly used to assess depression, the SCS used in adjunct may reveal additional information. While the BDI-II measures depression by evaluating the criteria for the diagnosis by the DSM-IV, the SCS measures the nature and quality of relationship one has with oneself. Furthermore, the subscales of the SCS may provide information to clinicians potentially guiding specific interventions targeted at subscales such as isolation or self-kindness. The SCS may also be appropriate for use with more fragile populations such as children or individuals with special needs.

Given the ease of administration and breadth of results, the SCS could be a potential asset for a clinician treating depression along with other psychological challenges. The SCS could provide insight to clinicians regarding how an individual's level of self-compassion could be affecting their life. Given the strong association with depression found in this study, using the SCS may inform clinicians in addressing its prevention or treatment. Prevention of depressive symptoms could be possible with periodically testing self-compassion levels with the SCS. In addition, treatment of depression could be approached with clients informed by the concept of self-compassion as a psycho-educational intervention.

The SCS may also provide an alternative or adjunct measurement of self-esteem and well-being in individuals. As many previous studies show, self-compassion correlates strongly with self-esteem and well-being (Neff, 2003b). The SCS may be 
helpful in increasing self-esteem and self-acceptance in individuals. Future exploration of self-compassion and self-esteem may point to aspects of self-compassion that are not accounted for by self-esteem. Furthermore, self-compassion encompasses the process of how one relates to oneself as opposed to their current state of being. This allows for a focus on process in psychotherapy or other treatment modalities. Lastly, given the challenges of solely focusing on self-esteem in therapy mentioned prior, promotion of self-compassion may account for additional areas of development in addition to the traditional notion of self-esteem.

The SCS shows promise for use in medical settings with a variety of medical diagnoses. As studies using MBSR and other treatments integrating self-compassion have demonstrated, there are numerous applications of mindfulness-based therapies in medicine. The SCS could be used in hospital intakes and medical evaluations to assess a patient's level of self-compassion. This could aid in understanding of a patient's state of being, and may inform adjunct therapies such as psychotherapy along with medical treatment. Using adjunct therapies informed by the SCS could potentially yield beneficial outcomes as some studies have indicated (Raque-Bogdan et al., 2011). Given the high degree of interconnection between physical and mental health, there may be multiple uses for the application of self-compassion focused therapies in medical settings.

The SCS has great potential as a measure for use with clinicians, caregivers, and other health care professionals in promoting self-care. Compassion fatigue and burnout are significant challenges in the caring professions, with a large percentage of clinicians facing these issues at some point in their careers (Craig \& Sprang, 2010). Self- 
compassion has been shown to have potential in maintaining sustainability among clinicians while reducing distress, anxiety, and negative affect (Shapiro, Brown, \& Biegel, 2007). This finding shows the potential for self-compassion and the SCS for use with clinicians. For example, the SCS could be used as a barometer for health care professionals to prevent or indicate the beginnings of burnout or compassion fatigue. Applications of self-compassion may play a role in ameliorating these effects. However, while preliminary findings regarding self-compassion and clinician self-care are promising, more studies are still needed.

In conclusion, the findings of this study indicate that the SCS shows promise for continued clinical and empirical applications. As the growing body of research suggests, many applications of the SCS exist. While the application of the SCS is still developing, further inquiry on the topic should provide more evidence for its use. Overall, the SCS offers a new insight into intra-personal dynamics that add breadth to the scope of our understanding of human functioning. As the growing body of research suggests, the SCS and self-compassion as a psychological construct are potentially valuable assets to be further explored.

\section{$\underline{\text { Future Directions }}$}

A number of changes could be applied to future studies concerning selfcompassion and the SCS. Using diverse population samples for future studies could provide more breadth regarding the validity of the SCS with various groups. This could also elucidate cultural, gender, age, and other comparisons. More diversity regarding clinical diagnoses and severity could also yield more clinically oriented results and would 
test the SCS with those populations. Furthermore, to depart from self-report methods, alternative experimental methods such as the induction of self-compassion could provide unique findings (Leary et al., 2007; Neff \& Vonk, 2009). Future self-report based studies could also provide more privacy and time for participants to complete questionnaires such as by taking them home or completing them in a private location.

Future studies of self-compassion and the SCS in particular could further their potential applications. While the SCS and self-compassion have been evaluated with a number of populations, settings, and clinical diagnoses, some areas could be further developed. The use of the SCS and role of self-compassion in the health care industry is one of these applications. Although studies have shown promise for SCS applications in healthcare and medicine, more studies need to be focused in this area. Similarly, more inquiry needs to made regarding self-compassion and self-care for clinicians, caregivers, and healthcare professionals. In addition, further research needs to be done with mindfulness and self-compassion focused therapies with children, adolescents, and families. Although there are some promising initial findings, many of the studies are characterized by few participants or other methodological issues. Furthermore, more research needs to be performed regarding the efficacy of self-compassion as a treatment intervention. These studies would benefit from rigorous research methods such as employing experimental and control groups in treatment settings.

Studies aimed at evaluating self-compassion and the SCS could also be aided by more rigorous empirical practices. As mentioned prior, future studies could evaluate the psychometric properties of the SCS by utilizing multiple inventories, especially 
inventories designed to measure similar constructs like mindfulness, self-judgment, or isolation that represent the SCS's subscales. Using multiple measures to evaluate discriminant and convergent validity of the SCS would provide more in-depth analysis of the SCS and information into the precise relationship of various measures and constructs. The scope of this study did not provide for a thorough investigation of the psychometrics of the SCS. While the results begin to form a picture of the psychometrics of the SCS, additional studies are still needed to make a complete and through assessment. 


\section{REFERENCES}

Aberson, C. L., Healy, M., \& Romero, V. (2000). Ingroup bias and self-esteem: A metaanalysis. Personality and Social Psychology Review, 4, 157-173.

Adams, C., \& Leary, M. (2007). Promoting self-compassionate attitudes toward eating among restrictive and guilty eaters. Journal of Social and Clinical Psychology, 26(10), 1120-1144.

Allen, N. B., Blashki, G., Chambers, R., Ciechomski, L., Gullone, E., Hassed, C., et al. (2006). Mindfulness-based psychotherapies: A review of conceptual foundations, empirical evidence and practical considerations. Australian and New Zealand Journal of Psychiatry, 40(4), 285-294.

Altmaier, E., \& Maloney, R. (2007). An initial evaluation of a mindful parenting program. Journal of Clinical Psychology, 63, 1231-1238.

American Psychiatric Association. (2000). Diagnostic and statistical manual of mental disorders (4th ed. text rev.). Arlington, VA: Author.

Arnau, R. C., Meagher, M. W., Norris, M. P., \& Bramson, R. (2001). Psychometric evaluation of the Beck Depression Inventory-II with primary care medical patients. Health Psychology, 20(2), 112-119.

Bach, P., \& Hayes, S. C. (2002). The use of acceptance and commitment therapy to prevent the re-hospitalization of psychotic patients: A randomized controlled trial. Journal of Consulting and Clinical Psychology, 70, 1129-1139.

Baer, R. (2003). Mindfulness training as a clinical intervention: A conceptual and empirical review. Clinical Psychology: Science and Practice, 10(2), 125-143. 
Baker, L., \& McNulty, J. (2011). Self-compassion and relationship maintenance: The moderating roles of conscientiousness and gender. Journal of Personality and Social Psychology, 100(5), 853-873.

Barnes, S., Brown, K. W., Krusemark, E., Campbell, W. K., \& Rogge, R. D. (2007). The role of mindfulness in romantic relationship satisfaction and responses to relationship stress. Journal of Marital and Family Therapy, 33(4), 482-500.

Baumeister, R. F., Bushman, B. J., Campbell, W. K. (2000). Self-esteem, narcissism, and aggression: Does violence result from low self-esteem or from threatened egotism? Current Directions in Psychological Science, 9, 26-29.

Baumeister, R. F., Smart, L., \& Boden, J. M. (1996). Relation of threatened egotism to violence and aggression: The dark side of high self-esteem. Psychological Review, 103, 5-33.

Baumeister, R. F., \& Vohs, K. D. (2001). Narcissism as addiction to esteem. Psychological Inquiry, 12, 206-210.

Beck, A. T. (1963). Thinking and depression: Idiosyncratic content and cognitive distortions. Archives of General Psychiatry, 9, 324-333.

Beck, A. T., Steer, R. A., \& Brown, G. (1996). Beck Depression Inventory II manual. San Antonio, TX: The Psychological Corporation.

Beck, A. T., Steer, R. A., Brown, G. K., \& van der Does, A. J. W. (2002). BDI-II-NL handleiding [BDI-II-Dutch manual]. Lisse, the Netherlands: Psychological Corporation.

Bennett-Goleman, T. (2001). Emotional alchemy: How the mind can heal the heart. New York: Three Rivers Press.

Biegel, G., Brown, K. , Shapiro, S. , \& Schubert, C. (2009). Mindfulness-based stress 
reduction for the treatment of adolescent psychiatric outpatients: A randomized clinical trial. Journal of Consulting \& Clinical Psychology, 77(5), 855-866.

Birnie, K., Speca, M. , \& Carlson, L. (2010). Exploring self-compassion and empathy in the context of mindfulness-based stress reduction (mbsr). Stress and Health: Journal of the International Society for the Investigation of Stress, 26(5), 359-371.

Bishop, S., Lau, M. , Shapiro, S. , Carlson, L. , Anderson, N. , Carmody, J., et al. (2004). Mindfulness: A proposed operational definition. Clinical Psychology: Science and Practice, 11(3), 230-241.

Blais, M. A., (2011). A guide to applying rating scales in clinical psychiatry. Psychiatric Times, 11, 2011. 58-62.

Bowlby, J. (1988). A secure base: Parent-child attachment and healthy human development. New York, NY: Books.

Brach, T. (2003). Radical acceptance: Embracing your life with the heart of a Buddha. New York: Bantam Books.

Brennan, K. A., Clark, C. L., \& Shaver, P. R. (1998). Self-report measurement of attachment: An integrative overview. In J. A. Simpson \& W. S. Rholes (Eds.), Attachment theory and close relationships (pp. 46-76). New York, NY: Guilford Press.

Brouwer, D., Meijer, R. R., \& Zevalkink, J. (2012). Brouwer, D. , Meijer, R. , \& Zevalkink, J. (2012). On the factor structure of the Beck Depression Inventory II: $\mathrm{G}$ is the key. Psychological Assessment, 7, 1-10. 
Brown, K. W. \& Ryan, R. M. (2003). The benefits of being present: Mindfulness and its role in psychological well-being. Journal of Personality and Social Psychology, $84,822-848$.

Brown, K. W., Ryan, R. M., Creswell, J. D., \& Niemiec, C. P. (2008). Beyond me: Mindful responses to social threat. In H. A. Wayment, \& J. J. Bauer (Eds.), Transcending self-interest: Psychological explorations of the quiet ego (pp. 75-84). Washington, DC: American Psychological Association.

Burke, C. (2010). Mindfulness-based approaches with children and adolescents: A preliminary review of current research in an emergent field. Journal of Child and Family Studies, 19(2), 133-144.

Burpee, L. C., \& Langer, E. J. (2005). Mindfulness and marital satisfaction. Journal of Adult Development, 12(1), 43-51.

Casher, M., Gih, D., \& Agarwala, P. (2012). Confounding factors in treatment-resistant depression: Comorbidities and treatment resistance. Psychiatric Times, 29(8), 43.

Chambers, R., Gullone, E. , \& Allen, N. (2009). Mindful emotion regulation: An integrative review. Clinical Psychology Review, 29(6), 560-572.

Chambers, R. H., Lo, B. C. Y., \& Allen, N. A. (2008). The impact of intensive mindfulness training on attentional control, cognitive style, and affect. Cognitive Therapy and Research, 32, 303-322.

Cicchetti, D. V. (1994). Guidelines, criteria, and rules of thumb for evaluating normed and standardized assessment instruments in psychology. Psychological Assessment, 6, 284-290. 
Coopersmith, S. (1967). The antecedents of self-esteem. San Francisco: W. H. Freeman.

Cordova, J. V., \& Jacobson, N. S. (1993). Couple Distress. In D. H. Barlow (Ed.), Clinical handbook of psychological disorders (pp. 481-512)., 2nd ed. New York: The Guilford Press.

Costa, J., \& Pinto-Gouveia, J. (2010). Acceptance of pain, self-compassion and psychopathology: Using the chronic pain acceptance questionnaire to identify patients' subgroups. Clinical Psychology \& Psychotherapy, 18(4), 292-302.

Craig, C. , \& Sprang, G. (2010). Compassion satisfaction, compassion fatigue, and burnout in a national sample of trauma treatment therapists. Anxiety, Stress \& Coping: An International Journal, 23(3), 319-339.

Crocker, J., \& Park, L. E. (2004). The costly pursuit of self-esteem. Psychological Bulletin, 130, 392-414.

Cusin, C., Yang, H., Yeung, A., \& Fava, M. (2010). Rating scales for depression. In Baer, L. \& Blais, M. (Eds.), Handbook of Clinical Rating Scales and Assessment in Psychiatry and Mental Health (pp. 7-35). New York: Humana Press.

Damon, W. (1995). Greater expectations: Overcoming the culture of indulgence in America's homes and schools. New York: Free Press.

Davidson, R. J., Kabat-Zinn, J., Schumacher, J., Rosenkranz, M., Muller, D., Santorelli, S. F., et al. (2003). Alterations in brain and immune function produced by mindfulness meditation. Psychosomatic Medicine, 65(4), 564-570.

Deniz, M., Kesici, S. , \& Sumer, A. (2008). The validity and reliability of the turkish version of the self-compassion scale. Social Behavior and Personality, 36(9), 
1151-1160.

Dozois, D. J. A., Dobson, K. S., \& Ahnberg, J. L. (1998). A psychometric evaluation of the Beck Depression Inventory-II. Psychological Assessment, 10, 83-89. doi: $10.1037 / 1040-3590.10 .2 .83$

Duncan, L. G., Coatsworth, J. D., \& Greenberg, M. T. (2009). A model of mindful parenting: Implications for parent-child relationships and prevention research. Child Clinical and Family Psychology Review, 12, 225-270.

Ellis, A., \& Dryden, W. (1997). The practice of rational-emotive behavior therapy. New York: Springer.

Ellis, A., \& London, T. (1993). The case against self-esteem: How the self-esteem movement is damaging our children and culture. Chicago: Garfield Press.

Evans, S., Ferrando, S., Findler, M., Stowell, C., Smart, C., \& Haglin, D. (2008). Mindfulness-based cognitive therapy for generalized anxiety disorder. Journal of Anxiety Disorders, 22(4), 716-721.

Fairburn, C. G., Cooper, Z., \& Shafran, R. (2003). Cognitive behavior therapy for eating disorders: A "transdiagnostic" theory and treatment. Behavioral Research and Therapy, 41(5), 509-528.

Fancher, R. (1995). Cultures of Healing: Correcting the image of American mental health care. New York: W. H. Freeman and Company.

Feeney, J. A. (2000). Implications of attachment style for patterns of health and illness. Child: Care, Health and Development, 26, 277-288.

Figley, C. R. (2002). Compassion fatigue: Psychotherapist's chronic lack of self care. Journal of Clinical Psychology, 58 (11, Suppl. 1), 1433-1441. 
Finn, C. E. (1990). Narcissus goes to school. Commentary, 89, 40-45.

Gambrel, L., \& Keeling, M. (2010). Relational aspects of mindfulness: Implications for the practice of marriage and family therapy. Contemporary Family Therapy: An International Journal, 32(4), 412-426.

Gaudiano, B. A., \& Herbert, J. D. (2006). Acute treatment of inpatients with psychotic symptoms using acceptance and commitment therapy: Pilot results. Behavior Research and Therapy, 44, 415-437.

Germer, C. K., Siegel, R. D., \& Fulton, P. R. (Eds.). (2005). Mindfulness and psychotherapy. New York: Guilford Press.

Gilbert, P. , \& Procter, S. (2006). Compassionate mind training for people with high shame and self-criticism: Overview and pilot study of a group therapy approach. Clinical Psychology \& Psychotherapy, 13(6), 353-379.

Goldstein, J., \& Kornfield, J. (1987). Seeking the heart of wisdom: The path of insight meditation. Boston: Shambala Publications.

Greco, L., \& Eifert, G. (2004). Treating parent-adolescent conflict: Is acceptance the missing link for an integrative family therapy?. Cognitive and Behavioral Practice, 11(3), 305-314.

Halifax, J. (2011). The precious necessity of compassion. Journal of Pain and Symptom Management, 41(1), 146-153.

Hanh, T. N. (1997). Teachings on love. Berkeley, CA: Parallax Press.

Hanh, T. N. (1976). The miracle of mindfulness: A manual for meditation. Boston: Beacon. 
Hanh, T. N. (2006). Understanding our mind. Berkeley, CA: Parallax Press.

Harter, S. (1999). The construction of the self: A developmental perspective. New York: Guilford Press.

Hayes, S. C., Strosahl, K. D., \& Wilson, K. G. (1999). Acceptance and commitment therapy: An experimental approach to behavior change. New York: Guilford Press.

Hayes, S. C., \& Wilson, K. G. (1994). Acceptance and commitment therapy: Altering the verbal support for experimental avoidance. The Behavior Analyst, 17, 289-303.

Heffernan, M., Griffin, M., McNulty, S., \& Fitzpatrick, J. (2010). Self-compassion and emotional intelligence in nurses. International Journal of Nursing Practice, 16(4), 366-373.

Hewitt, J. P. (1998). The myth of self-esteem: Finding happiness and solving problems in America. New York: St. Martin's Press.

Hofmann, S., Sawyer, A. , Witt, A. , \& Oh, D. (2010). The effect of mindfulness-based therapy on anxiety and depression: A meta-analytic review. Journal of Consulting \& Clinical Psychology, 78(2), 169-183.

Hollis-Walker, L., \& Colosimo, K. (2011). Mindfulness, self-compassion, and happiness in non-meditators: A theoretical and empirical examination. Personality and Individual Differences, 50(2), 222-227.

Hölzel, B. K., Ott, U., Gard, T., Hempel, H., Weygandt, M., Morgen, K., et al. (2007). Investigation of mindfulness meditation practitioners with voxel-based morphometry. Social Cognitive and Affective Neuroscience, 3(5), 55-61. 
Hughes, A., Williams, M., Bardacke, N., Duncan, L., Dimidjian, S., \& Goodman, S. H. (2009). Mindfulness approaches to childbirth and parenting. British Journal of Midwifery, 17(10), 630-635.

Huntsinger, E. T., \& Leuken, L. J. (2004). Attachment relationships and health behavior: The mediational role of self-esteem. Psychology \& Health, 19, 515-526.

Iskender, M. (2009). The relationship between self-compassion, self-efficacy, and control belief about learning in turkish university students. Social Behavior and Personality, 37(5), 711-720.

Jongsma, A. E., Peterson, L. M., \& Bruce, T. J. (Eds.). (2006). The complete adult psychotherapy planner. Hoboken, NJ: John Wiley \& Sons, Inc.

Kabat-Zinn, J. (1982). An outpatient program in behavioral medicine for chronic pain patients based on the practice of mindfulness meditation: Theoretical considerations and preliminary results. General Hospital Psychiatry, 4, 33-47.

Kabat-Zinn, J. (1990). Full catastrophe living: Using the wisdom of your mind to face stress, pain and illness. New York: Dell.

Kabat-Zinn, J. (1998). Meditation. In J. C. Holland (Ed.), Psycho-oncology (pp. 767-79). New York: Oxford University Press.

Kabat-Zinn, J. (1994). Wherever you go there you are. New York: Hyperion.

Kabat-Zinn, J., Lipworth, L., Burney, R., \& Sellers, W. (1987). Four-year follow-up of a meditation-based program for the self-regulation of chronic pain: Treatment outcome and compliance. Clinical Journal of Pain, 2, 159-173.

Kaplan, K. H., Goldenberg, D. L., \& Galvin-Nadeau, M. (1993). The impact of a 
meditation-based stress reduction program on fibromyalgia. General Hospital Psychiatry, 15(5), 284-289.

Kimbrough, E., Magyari, T. , Langenberg, P., Chesney, M. , \& Berman, B. (2010). Mindfulness intervention for child abuse survivors. Journal of Clinical Psychology, 66(1), 17-33.

Kristeller, J. L., \& Hallett, C. B. (1999). An exploratory study of a meditation-based intervention for binge eating disorder. Journal of Health Psychology, 4, 357-63.

Kuyken, W., Byford, S., Taylor, R. S., Watkins, E., Holden, E., White, K. et al. (2008). Mindfulness-based cognitive therapy to prevent relapse in recurrent depression. Journal of Consulting and Clinical Psychology, 76, 966-978.

Kuyken, W., Watkins, E., Holden, E., White, K., Taylor, R., Byford, S. et al. (2010). How does mindfulness-based cognitive therapy work?. Behaviour Research \& Therapy, 48(11), 1105-1112.

Laithwaite, H., Gumley, A., O'Hanlon, M., Collins, P., Doyle, P., Abraham, L., et al. (2009). Recovery after psychosis (rap): A compassion focused programme for individuals residing in high security settings. Behavioural and Cognitive Psychotherapy, 37(5), 511-526.

Lazar, S. W. (2005). Mindfulness research. In C. K. Germer, R. D. Siegel \& P.R. Fulton (Eds.), Mindfulness and psychotherapy. New York: The Guildford Press.

Leary, M., Tate, E., Adams, C., Allen, A., \& Hancock, J. (2007). Self-compassion and reactions to unpleasant self-relevant events: The implications of treating oneself kindly. Journal of Personality \& Social Psychology, 92(5), 887-904. 
Linehan, M. M. (1993). Cognitive-behavioral treatment of borderline personality disorder. New York: Guilford Press.

Linehan, M. M., Armstrong, H. E., Saurez, A., Allmon, D., \& Heard, H. L. (1991). Cognitive behavioral treatment of chronically parasuicidal borderline patients. Archives of General Psychiatry, 48, 1060-1064.

Lutz, A., Greischar, L. L., Rawlings, N. B., Ricard, M., \& Davidson, R. J. (2004). Longterm meditators self-induce high-amplitude gamma synchrony during mental practice. Proceedings of the National Academy of Sciences, 101, 16369-16373.

Ma, S. H., \& Teasdale, J. D. (2004). Mindfulness-based cognitive therapy for depression: Replication and exploration of differential relapse prevention effects. Journal of Consulting and Clinical Psychology, 72(1), 31-40.

Mayhew, S., \& Gilbert, P. (2008). Compassionate mind training with people who hear malevolent voices: A case series report. Clinical Psychology \& Psychotherapy, $15(2), 113-138$.

McKay, M., \& Fanning, P. (1992). Self-esteem: A proven program of cognitive techniques for assessing, improving, and maintaining your self-esteem (2nd ed.). Oakland, CA: New Harbinger.

McMillan, J. H., Singh, J., \& Simonetta, L. G. (1994). The tyranny of self-oriented selfesteem. Educational Horizons, Sp, 141-145.

Moore, A., \& Malinowski, P. (2008). Meditation, mindfulness and cognitive flexibility. Consciousness and Cognition: An International Journal, 18(1), 176-186.

Mosewich, A., Kowalski, K., Sabiston, C., Sedgwick, W., \& Tracy, J. (2011). Self- 
compassion: A potential resource for young women athletes. Journal of Sport \& Exercise Psychology, 33(1), 103-123.

Neff, K. (2003a). Self-compassion: An alternative conceptualization of a healthy attitude toward oneself. Self and Identity, 2(2), 85-101.

Neff, K. (2003b). The development and validation of a scale to measure self-compassion. Self and Identity, 2(3), 223-250.

Neff, K. (2009). The role of self-compassion in development: A healthier way to relate to oneself. Human Development, 52(4), 211-214.

Neff, K., Hsieh, Y., \& Dejitterat, K. (2004). Self-compassion, achievement goals, and coping with academic failure. Self and Identity, 4, 263-287.

Neff, K. D., Kirkpatrick, K., \& Rude, S. S. (2007). Self-compassion and its link to adaptive psychological functioning. Journal of Research in Personality, 41, $139-154$.

Neff, K., \& McGehee, P. (2010). Self-compassion and psychological resilience among adolescents and young adults. Self and Identity, 9, 225-240.

Neff, K., Pisitsungkagarn, K., \& Hsieh, Y. (2008). Self-compassion and self-construal in the united states, thailand, and taiwan. Journal of Cross-Cultural Psychology, 39(3), 267.

Neff, K. D., \& Rude, S. S., \& Kirkpatrick, K. (2007). An examination of self-compassion in relation to positive psychological functioning and personality traits. Journal of Research in Personality, 41, 908-916.

Neff, K., \& Vonk, R. (2009). Self-compassion versus global self-esteem: Two different 
ways of relating to oneself. Journal of Personality, 77(1), 23-50.

Orzech, K. , Shapiro, S. , Brown, K. , \& McKay, M. (2009). Intensive mindfulness training-related changes in cognitive and emotional experience. The Journal of Positive Psychology, 4(3), 212-222.

Patsiopoulos, A., \& Buchanan, M. (2011). The practice of self-compassion in counseling: A narrative inquiry. Professional Psychology, Research \& Practice, 42(4), 301-307.

Pauley, G. \& McPherson, S. (2010). The experience and meaning of compassion and self-compassion for individuals with depression or anxiety. Psychology and Psychotherapy: Theory, Research and Practice, 83, 129-143.

Pigni, A. (2010). A first-person account of using mindfulness as a therapeutic tool in the Palestinian Territories. Journal of Child and Family Studies, 19(2), 152.

Placone-Willey, P. M. (2002). A curriculum for mindful parenting: A model development dissertation. Unpublished dissertation.

Raes, F. (2010). Rumination and worry as mediators of the relationship between selfcompassion and depression and anxiety. Personality and Individual Differences. $48,757-761$.

Raes, F. (2011). The effect of self-compassion on the development of depression symptoms in a non-clinical sample. Mindfulness, 2(1), 33-36.

Raes, F., Pommier, E., Neff, K., \& Van Gucht, D. (2011). Construction and factorial validation of a short form of the self-compassion scale. Clinical Psychology \& Psychotherapy, 18(3), 250-255. 
Raque-Bogdan, T. L., Ericson, S. K., Jackson, J., Martin, H. M., \& Bryan, N. A. (2011). Attachment and mental and physical health: Self-compassion and mattering as mediators. Journal of Counseling Psychology, 58, 272-278.

Repetti, R. L., Taylor, S. E., \& Seeman, T. S. (2002). Risky families: Family social environments and the mental and physical health of the offspring. Psychological Bulletin, 128(2), 330-366.

Richardson, F., Fowers, B., \& Guignon, C. (1999). Re-envisioning psychology: Moral dimensions of theory and practice. San Francisco, CA: Jossey-Bass.

Riskind, J. H., Beck, A. T., Brown, G., \& Steer, R. A. (1987). Taking the measure on anxiety and depression: Validity of the reconstructed Hamilton scales. Journal of Nervous and Mental Disease 175, 474-479.

Rubia, K. (2009). The neurobiology of meditation and its clinical effectiveness in psychiatric disorders. Biological Psychology, 82(1), 1-11.

Salzberg, S. (1997). Lovingkindness: The revolutionary art of happiness. Boston: Shambala.

Sawyer-Cohen, J. \& Semple, R. (2010). Mindful parenting: A call for research. Journal of Child and Family Studies, 19, 145-151.

Schanche, E., Stiles, T., McCullough, L., Svartberg, M., \& Nielsen, G. (2011). The relationship between activating affects, inhibitory affects, and self-compassion in patients with cluster c personality disorders. Psychotherapy, 48(3), 293-303.

Schieman, S. (1999). Age and anger. Journal of Health and Social Behavior, 40(3), 273-289. 
Sedikides, C. (1993). Assessment, enhancement, and verification determinants of the selfevaluation process. Journal of Personality and Social Psychology, 65(2), $317-338$.

Segal, Z. V., Williams, J. M. G., \& Teasdale, J. D. (2002). Mindfulness-based cognitive therapy for depression: A new approach for preventing relapse. New York: Guilford Press.

Seligman, M. E. (1995). The optimistic child. Boston: Houghton Mifflin Co.

Shapiro, S., Brown, K., \& Biegel, G. (2007). Teaching self-care to caregivers: Effects of mindfulness-based stress reduction on the mental health of therapists in training. Training and Education in Professional Psychology, 1(2), 105-115.

Shapiro, S., Schwartz, G., \& Bonner, G. (1998). Effects of mindfulness-based stress reduction on medical and premedical students. Journal of Behavioral Medicine, 21(6), 581-599.

Shapiro, S. L., \& Carlson, L. E. (2009). The art and science of mindfulness: Integrating mindfulness into psychology and the helping professions. Washington DC: American Psychological Association.

Shaver, P. R., Lavy, S., Saron, C. D., \& Mikulincer, M. (2007). Social foundations of the capacity for mindfulness: An attachment perspective. Psychological Inquiry, 18(4), 264-271.

Shepherd, D., \& Cardon, M. (2009). Negative emotional reactions to project failure and the self-compassion to learn from the experience. Journal of Management Studies, 46(6), 923. 
Siegel, D. J. (2010). The mindful therapist: A clinician's guide to mindsight and neural integration. New York: W. W. Norton \& Company, Inc.

Singh, N., Lancioni, G., Winton, A., Singh, J., Singh, A., \& Wahler, R. G. (2010). Training in mindful caregiving transfers to parent-child interactions. Journal of Child and Family Studies, 19(2), 167.

Singh, N. N., Singh, A. N., Lancioni, G. E., Singh, J., Winton, A. S. W., \& Adkins, A. D. (2009). Mindfulness training for parents and their children with adhd increases the children's compliance. Journal of Child and Family Studies, 19(2), 157.

Smith, C. \& Erford, B. T. (1998). Test review: Beck Depression Inventory II. Association for Assessment in Counseling Education.

Speca, M., Carlson, L., Goodey, E., \& Angen, M. (2000). A randomized wait-list controlled trial: The effects of a mindfulness meditation based stress reduction program on mood and symptoms of stress in cancer outpatients. Psychosomatic Medicine, 62, 613-622.

Steer, R. A., Ball, R., Ranieri, W. F., \& Beck, A. T. (1997). Further evidence for the construct validity of the Beck Depression Inventory-II with psychiatric outpatients. Psychological Reports, 80, 443-446.

Swann, W. B. (1996). Self-traps: The elusive quest for higher self-esteem. New York: W. H. Freeman.

Tanaka, M., Wekerle, C., Schmuck, M., \& Paglia-Boak, A. (2011). The linkages among childhood maltreatment, adolescent mental health, and self-compassion in child welfare adolescents. Child Abuse and Neglect, 35(10), 887. 
Teasdale, J. D. (1999). Emotional processing, three modes of mind and the prevention of relapse in depression. Behaviour Research \& Therapy, 37, S53-S77.

Teasdale, J. D., Segal, Z. V., Williams, J. M. G., \& Mark, G. (1995). How does cognitive therapy prevent depressive relapse and why should attentional control (mindfulness) training help?. Behavior Research and Therapy, 33, 25-39.

Teasdale, J. D., Segal, Z. V., Williams, J. M. G., Ridgeway, V. A., Soulsby, J. M., \& Lau, M. A. (2000). Prevention of relapse/recurrence in major depression by mindfulness- based cognitive therapy. Journal of Consulting and Clinical Psychology, 68, 615-623.

Telch, C. F., Agras, W. S., \& Linehan, M. M. (2001). Dialectical behavior therapy for binge eating disorder. Journal of Consulting \& Clinical Psychology, 69(6), 1061-1065.

Terry, M., \& Leary, M. (2011). Self-compassion, self-regulation, and health. Self and Identity, 10(3), 352-362.

Van Dam, N., Sheppard, S., Forsyth, J., \& Earleywine, M. (2011). Self-compassion is a better predictor than mindfulness of symptom severity and quality of life in mixed anxiety and depression. Journal of Anxiety Disorders, 25(1), 123-130.

Wachs, K., \& Cordova, J. V. (2007). Mindful relating: Exploring mindfulness and emotion repertoires in intimate relationships. Journal of Marital and Family Therapy, 33(4), 464-481.

Walsh, J. J., Balint, M. G., Smolira Sj, D. R., Fredericksen, L. K., \& Madsen, S. (2009). Predicting individual differences in mindfulness: The role of trait anxiety, 
attachment anxiety and attentional control. Personality and Individual Differences, 46, 94-99.

Ward, L. C. (2006). Comparison of factor structure models for the Beck Depression Inventory-II. Psychological Assessment, 18, 81-88. doi:

$10.1037 / 1040-3590.18 .1 .81$

Wei, M., Liao, K., Ku, T., \& Shaffer, P. (2011). Attachment, self-compassion, empathy, and subjective well-being among college students and community adults. Journal of Personality, 79(1), 191-221.

Weiss, L. (2004). Therapist's guide to self-care. New York: Routledge.

Wright, M. A., Wren, A. A., Somers, T. J., Goetz, M. C., Fras, A. M., Huh, B. K. et al. (2011). Pain acceptance, hope, and optimism: Relationships to pain and adjustment in patients with chronic musculoskeletal pain. The Journal of Pain, 12(11), 1155-1162.

Ying, Y. (2009). Contribution of self-compassion to competence and mental health in social work students. Journal of Social Work Education, 45(2), 309. 
Table 1

Descriptive Analysis of Measures

\begin{tabular}{|c|c|c|c|c|}
\hline Measure & $M$ & $S D$ & Minimum & Maximum \\
\hline SCS Total Score & 2.82 & .76 & 1.38 & 4.46 \\
\hline Self-Kindness & 3.09 & .81 & 1.00 & 4.80 \\
\hline Self-Judgment & 2.86 & .98 & 1.00 & 5.00 \\
\hline Common Humanity & 3.29 & .97 & 1.25 & 5.00 \\
\hline Isolation & 2.83 & 1.07 & 1.00 & 5.00 \\
\hline Mindfulness & 3.51 & .81 & 1.00 & 5.00 \\
\hline Over-Identification & 2.96 & 1.02 & 1.00 & 5.00 \\
\hline BDI-II Total Score & 8.82 & 7.73 & 0.00 & 40.00 \\
\hline Cognitive-Affective & 3.37 & 3.64 & 0.00 & 22.00 \\
\hline Somatic-Vegetative & 5.46 & 4.64 & 0.00 & 21.00 \\
\hline
\end{tabular}


Table 2

Intercorrelations Between Scales and Subscales

\begin{tabular}{llllllllll}
1 & 2 & 3 & 4 & 5 & 6 & 7 & 8 & 9 & 10 \\
\hline
\end{tabular}

1. SCS (Total) 1

2. SK $\quad .82 \quad 1$

3. SJ $\quad-.84 \quad-.67 \quad 1$

4. $\mathrm{CH} \quad \begin{array}{llll}\mathrm{CH} & .53 & -.38 & 1\end{array}$

$\begin{array}{llllll}\text { 5. I } & -.80 & -.50 & .68 & -.38 & 1\end{array}$

$\begin{array}{lllllll}\text { 6. } \mathrm{M} & .78 & .64 & -.50 & .59 & -.49 & 1\end{array}$

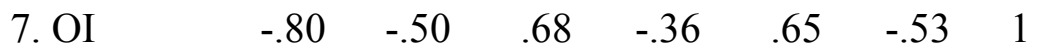

$\begin{array}{lllllllll}\text { 8. BDI-II } & -.57 & -.35 & .49 & -.37 & .59 & -.35 & .43 & 1\end{array}$

$\begin{array}{llllllllll}\text { 9. Cog-Aff } & -.56 & -.35 & .54 & -.36 & .53 & -.34 & .47 & .91 & 1\end{array}$

$\begin{array}{lllllllllll}\text { 10. Som-Veg } & -.50 & -.31 & .39 & -.34 & .56 & -.31 & .42 & .95 & .74 & 1\end{array}$

Key: 1. Self-Compassion Scale (SCS); 2. Self-Kindness Subscale(SK); 3. Self-Judgment Subscale (SJ); 4. Common Humanity Subscale (CH); 5. Isolation Subscale (I); 6.

Mindfulness Subscale (M); 7. Over-Identification Subscale (OI); 8. Beck Depression Inventory II (BDI-II); 9. Cognitive-Affective Subscale (Cog-Aff); 10. Somatic-Vegetative Subscale (Som-Veg).

All correlations are significant $(p<.001)$. 
Table 3

Intercorrelations Between SCS and BDI-II Scores for Males and Females

\begin{tabular}{lllll}
\hline & 1 & 2 & 3 & 4 \\
\hline & Males $(\mathrm{n}=38)$ & & \\
1. SCS (Total) & 1 & & & \\
2. BDI-II & -.67 & 1 & 1 \\
3. Cognitive-Affective (BDI-II) & -.66 & .89 & .67 & 1 \\
4. Somatic-Vegetative (BDI-II) & -.57 & .94 & & \\
\hline
\end{tabular}

Females $(\mathrm{n}=104)$

1. SCS (Total) 1

2. BDI-II $-.54 \quad 1$

3. Cognitive-Affective (BDI-II) $\quad-.54 \quad 92 \quad 1$

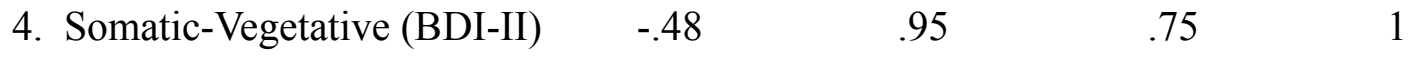


Appendix A

\section{Informed Consent Form}

\section{INFORMED CONSENT TO PARTICIPATE IN: Validation Study of the Self-Compassion Scale (SCS)}

A research project on Self-Compassion is being conducted by Pär Andréasson in the Department of Psychology and Child Development at Cal Poly, San Luis Obispo. The purpose of the study is to assess the validity of the "Self-Compassion Scale" as it relates to other, more established inventories.

You are being asked to take part in this study by completing the attached/enclosed questionnaires. You will be asked to complete the attached questionnaires either in your classroom or at a location of your choosing. Your participation will take approximately 15-30 minutes. Please be aware that you are not required to participate in this research and you may discontinue your participation at any time without penalty. You may also omit any items on the questionnaires you prefer not to answer.

The possible risks associated with participation in this study include possible feelings of depression, anxiety, and/or emotional distress. If you should experience any of the above stated emotional states, please be aware that you may contact Cal Poly Health and Counseling Services at (805) 756-2511 or the Community Counseling Center at (805) 543-7969 for assistance.

Your responses will be provided anonymously to protect your privacy. Potential benefits associated with the study include increased awareness of your emotional state and level of compassion for yourself. Other benefits include adding to the breadth and depth of research on the topic of Self-Compassion as it applies to individual psychological functioning. You may also be eligible to receive general psychology course research participation or extra credit as a subject in this investigation.

If you have questions regarding this study or would like to be informed of the results when the study is completed, please feel free to contact Pär Andréasson or Jason Williams at (805) 234-0607 and (805) 756-2886 respectively. If you have concerns regarding the manner in which the study is conducted, you may contact Dr. Steve Davis, Chair of the Cal Poly Human Subjects Committee, at 756-2754, sdavis@calpoly.edu, or Dr. Susan Opava, Dean of Research and Graduate Programs, at 756-1508, sopava(a,calpoly.edu.

If you agree to voluntarily participate in this research project as described, please indicate your agreement by completing and returning the attached questionnaires. Please retain this consent cover form for your reference, and thank you for your participation in this research. 


\section{Appendix B}

\section{HOW I TYPICALLY ACT TOWARDS MYSELF IN DIFFICULT TIMES}

Please read each statement carefully before answering. To the left of each item, indicate how often you behave in the stated manner, using the following scale:

\section{Almost never}

1 2
3
Almost always

4
5

1. I'm disapproving and judgmental about my own flaws and inadequacies.

2. When I'm feeling down I tend to obsess and fixate on everything that's wrong.

3. When things are going badly for me, I see the difficulties as part of life that everyone goes through.

4. When I think about my inadequacies, it tends to make me feel more separate and cut off from the rest of the world.

5. I try to be loving towards myself when I'm feeling emotional pain.

6. When I fail at something important to me I become consumed by feelings of inadequacy.

7. When I'm down and out, I remind myself that there are lots of other people in the world feeling like I am.

8. When times are really difficult, I tend to be tough on myself.

9. When something upsets me I try to keep my emotions in balance.

10. When I feel inadequate in some way, I try to remind myself that feelings of inadequacy are shared by most people.

11. I'm intolerant and impatient towards those aspects of my personality I don't like.

12. When I'm going through a very hard time, I give myself the caring and tenderness I need.

13. When I'm feeling down, I tend to feel like most other people are probably happier than I am.

14. When something painful happens I try to take a balanced view of the situation. 
15. I try to see my failings as part of the human condition.

16. When I see aspects of myself that I don't like, I get down on myself.

17. When I fail at something important to me I try to keep things in perspective.

18. When I'm really struggling, I tend to feel like other people must be having an easier time of it.

19. I'm kind to myself when I'm experiencing suffering.

20. When something upsets me I get carried away with my feelings.

21. I can be a bit cold-hearted towards myself when I'm experiencing suffering.

22. When I'm feeling down I try to approach my feelings with curiosity and openness.

23. I'm tolerant of my own flaws and inadequacies.

24. When something painful happens I tend to blow the incident out of proportion.

25. When I fail at something that's important to me, I tend to feel alone in my failure.

26. I try to be understanding and patient towards those aspects of my personality I don't like. 